\title{
Plant-wide Control of Coupled Distillation Columns with Partial Condensers
}

\author{
Edris Ebrahimzadeh $^{\mathrm{a}^{*}}$ and Larry L. Baxter ${ }^{\mathrm{a}, \mathrm{b}^{* *}}$ \\ ${ }^{a}$ Chemical Engineering Department, Brigham Young University, Provo, UT, USA \\ ${ }^{\mathrm{b}}$ Sustainable Energy Solutions, LLC, Orem, UT, USA
}

*Corresponding author: Edris Ebrahimzadeh (edris.put@byu.edu)

${ }^{* *}$ Corresponding author: Larry L. Baxter (1arry_baxter@byu.edu)

\section{Abstract}

Conventional distillation control processes use vapor distillate flowrate to control column pressure and condenser heat removal to control the reflux drum level. These intuitive control systems work well for isolated columns or columns with total condensers. However, these controls are not effective when columns with partial condensers occur in series. The pressure and reflux drum level interact in such systems in ways that defeat conventional control systems, rendering them unable to maintain product purities in the presence of large feed flowrate and composition disturbances. This investigation documents a plant-wide control structure that can address this issue by controlling pressure through reflux heat removal rate and reflux drum level by reflux flow rate. This control system demonstrates its capability to handle large disturbances in throughput and feed composition through a series of Aspen simulations. This alternative system is no more complicated than the conventional system and should work on distillation columns of nearly all designs, not just the coupled partial condenser designs for which it is essential.

Common natural gas processing provides a specific example of this alternative control system. Natural gas commonly includes high concentrations of $\mathrm{CO}_{2}$ that must be removed prior to pipeline or LNG distribution. The existence of a minimum-boiling temperature azeotrope between ethane, virtually always 
1 present in natural gas, and carbon dioxide complicates the separation of $\mathrm{CO}_{2}$ from the hydrocarbons. This

2 separation commonly employs extractive distillation with high-molecular-weight hydrocarbons. Our

3 recent paper [1] discusses in detail the steady-state economic design of a new extractive distillation

4 strategy for the $\mathrm{CO}_{2}$-ethane azeotrope separation with three columns. This strategy shows a $5 \%$ reduction

5 in capital and $15 \%$ reduction in operating costs when compared to optimized versions of the conventional

6 process. The new strategy also produces $\mathrm{CO}_{2}$ in a liquid rather than a vapor phase, which simplifies

7 transport, storage, and handling. Two columns of the proposed design use partial condensers and are the

8 focus of this investigation.

9 Keywords: Extractive distillation, $\mathrm{CO}_{2}$-ethane azeotrope, Simulation, Control, Aspen Plus Dynamics.

\section{Introduction}

11 Natural gas has a long-established role as a major primary energy source domestically and internationally.

12 Recently, U.S. natural gas supplies and consumption have increased significantly and US natural gas

13 prices, for the first time, decoupled from petroleum prices. International supply and consumption changes

14 are more measured and in many regions prices remain tied to petroleum prices. By all reasonable

15 accounts, natural gas will remain and probably become an increasingly important primary energy source

16 into the foreseeable future [2-4].

17 Natural gas processing includes four stages: acid gas removal, dehydration, condensate removal, and

18 liquefaction [5]. The acid gas removal process, or sweetening, removes $\mathrm{CO}_{2}$ and $\mathrm{H}_{2} \mathrm{~S}$ from the natural gas.

19 The separation of these gases is crucial for increasing the heating value of LNG, and preventing the

20 solidification of $\mathrm{CO}_{2}$ during subsequent steps [6-10].

21 There are several methods for natural gas sweetening, such as chemical absorption with amines, physical

22 absorption, membrane permeation, and cryogenic distillation processes. Of these practices, absorption

23 with amines is the most widely used. The main disadvantages of this process are the significant 
1 consumption of solvent for high $\mathrm{CO}_{2}$ concentration feedstock and significant safety and operational

2 issues. Moreover, this process produces a low-pressure gaseous $\mathrm{CO}_{2}$ product that often requires

3 liquefaction for further use. Similarly, the membrane $\mathrm{CO}_{2}$ removal process produces a low-pressure $\mathrm{CO}_{2}$

4 product that suffers from the issue of high pressure drop.

5 The cryogenic extractive distillation process has the potential to overcome some of the abovementioned

6 issues [11]. To apply this process, two significant challenges must be addressed: first, the sublimation of

$7 \quad \mathrm{CO}_{2}$ in the demethanizer column, and second, the existence of a minimum-boiling azeotrope between

8 ethane and $\mathrm{CO}_{2}$. To overcome these challenges, a fraction of the NGL product from the recovery column

9 recycles back as a solvent in the demethanizer column. The solvent contains a mixture of propane and

10 heavier hydrocarbons $\left(\mathrm{C}_{3}+\right)$ from the original gas feed and serves as an entrainer by taking $\mathrm{CO}_{2}$ to the

11 bottom of the column, thus reducing the freezing point of $\mathrm{CO}_{2}$ and preventing solid $\mathrm{CO}_{2}$ formation.

12 Moreover, the solvent aids in breaking the $\mathrm{CO}_{2}$-ethane azeotrope in the extractive distillation column.

13 There is a rich literature on the subject of azeotropic systems. Doherty and Malone [12], and Stichlmair 14 and Fair [13] provide notable examples of azeotropic separation phase equilibrium for both binary and 15 ternary systems. Hong and Kobayashi [14] provide vapor-liquid equilibrium (VLE) data for the separation 16 of $\mathrm{CO}_{2}$ and ethane using $n-\mathrm{C}_{5}$ as a solvent in the extractive distillation process. Torres-Ortega [15] 17 investigate an alternative thermally coupled sequence (CEDSR) configuration based on a cryogenic 18 extractive distillation system to enhance the carbon dioxide removal with lower total annual cost. They 19 also study the effect of different liquefied hydrocarbon fractions as an entrainer, the greenhouse gases 20 generation, the theoretical control properties, and the thermodynamic efficiency of the proposed system.

21 They conclude that the proposed configuration has better performances than the conventional chemical 22 absorption process. Lastari et al. [16] study the effects of solvent-to-feed ratio, feed tray locations, and 23 solvent composition on the energy demand of the extractive distillation for azeotrope separation of $\mathrm{CO}_{2}$ 24 and ethane. 
1 Tavan et al. [17, 18] discuss the application of feed splitting technique in extractive distillation for the

$2 \mathrm{CO}_{2}$-ethane azeotrope separation. They observed that feed-splitting scheme has superior performance in

3 terms of total energy requirement and environmental impacts compared with the conventional method.

4 Tavan et al. [19] investigate the application of the dividing-wall column (DWC) process for the

5 azeotropic separation of $\mathrm{CO}_{2}$ and ethane at low temperatures and compare the economic and

6 environmental aspects of the DWC process with the conventional process. Tavan et al. [20, 21] explore

7 the application of reactive absorption (RA) to break the $\mathrm{CO}_{2}$-ethane azeotrope with low energy demand

8 and compare their results with the conventional extractive distillation system. They optimize

9 diethanolamine (DEA) flow rate, DEA inlet temperature, and feed inlet stage with respect to process

10 energy requirement. In another investigation [22], Tavan et al. investigate $\mathrm{CO}_{2}$-ethane azeotropic mixture

11 as the feed of a reforming process to convert $\mathrm{CO}_{2}$ and ethane to syngas $\left(\mathrm{H}_{2}\right.$ and $\left.\mathrm{CO}\right)$. They recommend

12 Mg-type catalysts and a minimum steam/HC ratio of 1.5 to avoid coke formation during reforming

13 process.

14 These methods, however, have a significant drawback: the high energy requirement and/or equipment

15 cost leads to penalties in the operating and capital expenses (OpEx and CapEx), as well as long payback

16 period times [23]. A previously disclosed novel extractive distillation system reduces these costs for $\mathrm{CO}_{2^{-}}$

17 ethane separation using a three-column configuration that meets the desired purification with $5 \%$ less

18 capital costs and $15 \%$ less energy requirement compared to conventional systems. This new process also

19 produces $\mathrm{CO}_{2}$ as a liquid product, which avoids the significant amount of energy required for liquefaction

$20[1]$.

21 This new process has one total condenser column and two partial condenser columns. Conventional

22 distillation control systems follow intuitive reasoning and control pressure by manipulating vapor

23 distillate flowrate and reflux drum level by manipulating condenser heat removal. However, the

24 interaction among the pressure, reflux drum level and tray temperature control loops cause the

25 conventional control structure to fail in maintaining the purity of the products in the presence of large 
1 disturbances in throughput and feed compositions when the vapor distillate stream feeds another

2 distillation column.

3 The main purpose of this investigation is to develop an effective control structure that can address the

4 issue of plant-wide control of distillation column systems that have interconnected partial condenser and

5 total condenser columns. Aspen Plus and Aspen Dynamics tools provide rigorous steady-state and

6 dynamic simulations.

\section{Thermodynamic Analysis}

8 Figure 1 exhibits the phase equilibrium diagram of the binary mixture of $\mathrm{CO}_{2}$-ethane at the pressure of 20

9 bar. The boiling points of $\mathrm{CO}_{2}$ and ethane at this pressure are 254.13 and $265.81 \mathrm{~K}$, respectively. The

10 figure clearly shows that $\mathrm{CO}_{2}$ and ethane form a minimum-boiling homogenous binary azeotrope at 0.65

11 mole fraction $\mathrm{CO}_{2}$ at $247.71 \mathrm{~K}$. The azeotrope occurs because of the strong molecular repulsion forces

12 between ethane and $\mathrm{CO}_{2}$. Methods to separate binary azeotropes fall into two categories:

13 1. Azeotropic distillation systems- which require the addition of a third chemical component, or entrainer, that shifts the azeotropic composition. The azeotropic distillation systems function in two ways. A light entrainer forms on of at least two distillate or overhead components in the "azeotropic" column. These generally immiscible components separate in a decanter. One phase refluxes the first column, whereas the second phase feeds another distillation column to regenerate the solvent, which recycles to the first column. A heavy entrainer forms one of at least two components in bottoms of the extractive column. These generally miscible components feed a separate distillation column, which recycles the entrainer to the first column. These methods constitute azeotropic distillation and extractive distillation, respectively.

2. Pressure-swing distillation- which does not require the addition of a third component (entrainer) to shift the vapor-liquid equilibrium. Two columns operating at two different pressures can achieve separation if changes in pressure significantly alter the relative volatilities. 
1 Figure 2 shows that pressure changes do not shift the vapor-liquid equilibrium of ethane- $\mathrm{CO}_{2}$ mixture

2 considerably, indicating that pressure-swing distillation is generally an inefficient method for this

3 separation. However, Figure 3 clearly demonstrates that high molecular weight hydrocarbons such as n-

4 butane change the VLE of the system. Figure 3(a) shows that the addition of the entrainer decreases the

5 freezing point of $\mathrm{CO}_{2}$ to $-67.3{ }^{\circ} \mathrm{C}$, which prevents the solidification of $\mathrm{CO}_{2}$ at low temperatures. Figure

6 3(b) illustrates that all the residue curve lines start at the minimum-boiling azeotrope and move toward the

7 highest boiling component $n-C_{4}$. Therefore, extractive distillation is a viable method for the separation in

8 the presence of a miscible mixture and a homogenous azeotrope.

\section{Process Flowsheet}

10 Figure 4 shows the flowsheet for the proposed alternative distillation sequence. The feed stream 11 comprises a bottoms stream from a de-methanizer column and includes carbon dioxide, ethane, and 12 higher molecular weight hydrocarbons. The process contains three columns: the $\mathrm{CO}_{2}$ recovery column, 13 the solvent recovery column, and the concentrator column. In this process, not all the $\mathrm{CO}_{2}$ exits at the 14 overhead of the extraction column. The bottom product of the extraction column, which contains some of 15 the $\mathrm{CO}_{2}$ in the fresh feed along with most of the ethane and heavier hydrocarbons, feed the second column. This column also produces high-purity solvent as the bottoms stream. The recovery column

17 distillate vapor is an azeotropic mixture, which recycles to the initial feed. The recovery column bottoms stream is the ethane product.

\subsection{Extractive Column}

20 The extractive column has 39 stages and operates at the pressure of 24 atm. The fresh feed gas and the 21 solvent stream enter at stages 36 and 5, respectively. The solvent in the extractive column alters the 22 relative volatility between ethane and $\mathrm{CO}_{2}$, driving ethane to the bottom of the column and $\mathrm{CO}_{2}$ overhead.

23 The section above the entrainer feed location in the column separates the entrainer and $\mathrm{CO}_{2}$. The section 24 between the entrainer feed stage and the fresh feed stage prevents ethane from going up the column. The 
1 section below the fresh feed location prevents $\mathrm{CO}_{2}$ from going down the column. The extractive column

2 delivers a $\mathrm{CO}_{2}$-rich distillate $(95.7 \mathrm{~mol} \%)$ with impurities of $2.9 \mathrm{~mol} \%$ ethane and $1.3 \mathrm{~mol} \%$ propane.

3 The bottoms stream carries most of the ethane, some of the $\mathrm{CO}_{2}$ in the fresh feed, and heavier

4 hydrocarbons to the solvent recovery column.

\subsection{Solvent Recovery Column}

6 The solvent recovery column has 37 stages and the bottom stream of the extractive column enters as a

7 feed on stage 15 . The distillate has $0.3 \mathrm{~mol} \% n-\mathrm{C}_{3}$, whereas the bottoms stream has 0.05 mol $\%$ ethane 8 and the remainder heavier hydrocarbons. This stream splits (after heat exchange) into the NGL product 9 and the solvent feed streams, the latter of which recycles back to the first column. The NGL stream passes 10 through a sequence of traditional distillation columns for $\mathrm{C}_{3}, \mathrm{C}_{4}$ and $\mathrm{C}_{5}$ recoveries. The distillate is a 11 mixture of almost $80 \mathrm{~mol} \%$ ethane and $20 \mathrm{~mol} \% \mathrm{CO}_{2}$ that needs to be concentrated before recycling to 12 the extractive column.

\subsection{Concentrator Column}

14 The third column has 43 stages and the distillate of the recovery column enters on stage 10 . This column 15 produces an ethane-rich stream $(99.5 \mathrm{~mol} \%)$ as the bottom product. The azeotropic mixture of ethane and $16 \mathrm{CO}_{2}$ goes overhead with the $\mathrm{CO}_{2}$ concentrated up to $46 \mathrm{~mol} \%$.

\section{Plant-wide Control}

18 Process control investigations extensively analyze distillation control. Distillation columns differ in 19 operating conditions, product purity specifications, difficulty of separation, differences in feed contents,

20 column constraints, and local economic parameters, requiring many different control schemes [24].

21 Steady-state analyses greatly outnumber transient analyses [25-39].

22 Partial condenser column control is challenging because of the interaction among the reflux drum level, 23 pressure and tray temperature in the control loops. The literature dealing with the control of a distillation 
1 column with a partial condenser is limited, and to the best of the authors' knowledge, there is no analysis

2 covering the control of distillation column systems that have interconnected partial condensers and a total

3 condenser column. Such systems introduce unique control problems, as discussed later.

4 Buckley [40] and Shinskey [41] pioneer studying the design and control of distillation columns with 5 partial condensers. Luyben [24] examine the fundamental dynamic relationship of a distillation column 6 with partial condenser and proposed three alternatives for the control of distillation columns with partial 7 condensers. Hori and Skogestad [42] investigate alternative control structures for a cryogenic deethanizer 8 column with a partial condenser and implemented the best control structure on a real column. Luyben 9 [43] demonstrates a realistic model for distillation columns with partial condensers producing both liquid 10 and vapor products. He reports that the model assuming a fixed flowrate of cooling water provides the 11 most realistic performance predictions to disturbances. Grassi [44] set the standard configuration for the 12 control of extractive distillation columns and suggests a control structure that uses single-end temperature 13 control for both columns with the solvent flowrate ratioed to feed flowrate.

14 The overall molar balance around the reflux drum of a distillation column with partial condenser leads to,

$$
\frac{d N_{R}}{d t}=L_{c}-R
$$

15 where $N_{R}$ is the molar holdup of liquid in the reflux drum, $L_{c}$ is the flowrate of the outgoing liquid from 16 the condenser, and $R$ is the reflux flowrate. The following equation relates the liquid flowrate to the 17 condenser heat duty,

$$
L_{c}=\frac{Q_{c}}{\Delta H_{v}}
$$




$$
\frac{d N_{R}}{d t}=\frac{Q_{c}}{\Delta H_{v}}-R
$$

1 The above equation shows how reflux flowrate and condenser heat removal directly affect the reflux 2 drum level while the overhead vapor flowrate does not.

3 Moreover, applying the overall mole balance around the vapor space in the reflux drum gives,

$$
\frac{V_{d}}{R T_{R}} \frac{d P}{d t}=V_{N}-L_{C}-D
$$

4 which equates to,

$$
\frac{V_{d}}{R T_{R}} \frac{d P}{d t}=V_{N}-\frac{Q_{c}}{\Delta H_{v}}-D
$$

5 where $V_{d}$ is volume of the vapor, $T_{R}$ is the reflux drum temperature, $V_{N}$ is the vapor flowrate leaving the 6 top tray, $D$ is the vapor distillate flowrate, and $R$ is the ideal gas law constant. Eq. (5) clearly shows that 7 both distillate flowrate and condenser heat removal affect the pressure. This is the main cause of the 8 interaction between the level and pressure loops in a partial condenser. The parameter $V_{N}$ indicates the 9 load disturbance.

Applying the Laplace transform to rearrange the above equations in the form of transfer functions gives,

$$
\begin{gathered}
P(s)=-\left[\frac{R T_{R}}{V_{d} \Delta H_{v} s}\right] Q_{c}(s)-\left[\frac{R T_{R}}{V_{d} \Delta H_{v} s}\right] D(s) \\
N_{R}(s)=\left[\frac{1}{\Delta H_{v} s}\right] Q_{c}(s)-\left[\frac{1}{s}\right] R(s)
\end{gathered}
$$

11 These equations clearly show that pressure is a function of condenser heat removal and vapor distillate,

12 but not the reflux flowrate. Moreover, the reflux drum level is a function of condenser heat removal and 13 reflux flowrate, but not the vapor distillate flow. 
1 The ideal control structure of a distillation column would measure the impurity of the light-key

2 component in the bottoms and the impurity of the heavy-key component in the distillate and manipulate

3 two input variables to maintain the desired impurities in the two product streams. However, this ideal

4 control structure is barely used for distillation columns because composition analyzers; (1) are expensive

5 to purchase affiliated with their high maintenance costs, (2) do not always provide reliable results for

6 online continuous control, and (3) introduce long measurement lags into the control loop when

7 chromatographic methods are applied. However, it is possible to attain very effective control without

8 using direct composition measurement. Single-end inferential control structures commonly provide

9 inferential composition control for distillation columns. Thermocouples are cheap and introduce small

10 dead time in the control loop. Appropriately chosen locations for temperatures provide reliable

11 information about the key components composition.

12 This investigation explores two control structures. The first structure (CS I) uses conventional controls for

13 partial condenser columns in which vapor distillate flowrate controls column pressure and condenser heat

14 removal controls reflux drum level. The second control structure (CS II) controls column pressure by

15 condenser heat removal and controls drum level by reflux flowrate. Valve pressure drops and pump heads

16 are $3 \mathrm{~atm}$ to give reasonable rangeability so that valve saturation does not occur in the face of large

17 increases in feed throughput. The reflux drums and the column bases provide 5 min of liquid holdup

18 when the vessel is half-full at the design conditions.

\subsection{Control Structure CS I (Conventional Control Structure)}

20 Figure 5 presents the CS I control structure for the new $\mathrm{CO}_{2}$-ethane separation process. Proportional

21 controllers with $K_{c}=2$ are applied for level loops, whereas conventional proportional-integral actions are

22 used for the remainder of the system.

23 The CS I control structure includes the following features; 
1. Feed and recycle streams are flow-controlled.

2. Solvent is ratioed to feed.

3. Base level in each column is controlled by manipulating the bottoms flow.

4. Reflux drum in the extraction column is controlled by manipulating the distillate flow.

5. Reflux drum in the solvent recovery and the concentrator columns are controlled by manipulating the corresponding condenser heat removal.

6. Pressure in the extraction column is controlled by manipulating the condenser heat removal.

7. Pressure in the solvent recovery column and the concentrator is controlled by manipulating the corresponding vapor distillate flows.

8. The reflux flow in the extraction column is ratiod to the feed.

9. The reflux flows in the solvent recovery and the concentrator columns remain constant.

10. A temperature in each column is controlled by manipulating the corresponding reboiler heat input.

Partial condenser columns (the second and third columns of this process) require both pressure and reflux drum level control. There are several manipulated variables available: distillate flowrate, condenser heat removal and reflux flowrate. In a partial condenser column, the distillate flows from the reflux drum in the form of a vapor stream. The vapor distillate cannot directly control the reflux drum level because the drum level does not depend on the vapor flowrate. Practically, it is also typically quite difficult to meter.

Conventional systems control pressure by manipulating distillate vapor flowrate. There is an interaction between the pressure and control loop in this configuration because any disturbance affecting either loop will propagate to the other loop. For instance, assume the feed composition changes and more $\mathrm{CO}_{2}$ enters the column. This reduces the reflux drum temperature, and as a result, decreases the heat transfer rate in the condenser for a fixed flowrate of refrigerant. As the condensation rate decreases, the pressure increases, and the pressure controller increases the vapor distillate flowrate. Additionally, the drop in condensation rate decreases the reflux drum level. As a result, the level controller increases the refrigerant flowrate to compensate, which decreases the pressure. This interaction places the level controller and the pressure controller into a cyclic, potentially unstable interaction. 
1 Figure 6(a) shows the temperature profile of the extraction column whereas Figure 6(b) shows the

2 composition profiles of the key components in the extractive column. The slope of the temperature profile

3 (Figure 6(c)) and the slope of the composition profiles (Figure 2(d)), indicate that the temperatures and

4 the key components compositions change rapidly from tray to tray around stage 24 of the extractive

5 column. If the temperature of stage 24 remains at $271 \mathrm{~K}$, the heavy components should not escape out the

6 top, and light components would not drop out the bottom. Figure 7 shows that holding stage 24 at $334 \mathrm{~K}$

7 in the solvent recovery column maintains the purity of the products at the design specs. These simulations

8 use dead-times of $1 \mathrm{~min}$ in each temperature loop. Relay-feedback tests use the conservative Tyreus-

9 Luyben tuning settings to obtain the temperature controller tuning constants.

\subsubsection{CS I Results}

11 Simulated large disturbances in feed flowrate and composition help evaluate the effectiveness of this 12 control structure. In the first case uses $20 \%$ increases in feed flowrate at time equal $0.5 \mathrm{~h}$ with the results 13 shown in Figure 8 by solid lines. Manipulating the reboiler heat inputs controls the temperature of each 14 column. Figure 8(a) shows that distillate purity in the extractive column $x_{\mathrm{CO}_{2}}$ remains constant and close 15 to the specification. However, bottoms purity in the concentrator column $x_{C_{2}}$ drops significantly (Figure

16 8(c)). This occurs because condenser heat removal controls column pressure. The higher throughput 17 decreases reflux drum temperature, which decreases heat transfer rate in the condenser for a fixed

18 flowrate of the refrigerant. Therefore, column pressure begins to increase, which leads to increases in the 19 vapor distillate flowrate. The decrease in the condensation rate results in a decrease of the reflux drum 20 level. The decrease in the reflux drum level makes the level controller compensate by increasing the 21 refrigerant flowrate, which leads to a pressure decrease. This coupling between the level controller and 22 the pressure controller causes large and rapid changes in the vapor distillate flowrate. Since this vapor 23 distillate is the feed of another column, any variation in this stream propagates to the downstream process 24 and upsets it as well. As a result, the bottoms purity $x_{C 2}$ in the third column drops from $99.5 \%$ to $92 \%$. 
1 Feed composition perturbations lead to similar results. The simulations present results where the ethane

2 mole fraction in the feed increases by $5 \%$ with a corresponding $5 \%$ decrease in $\mathrm{CO}_{2}$ mole fraction at time

3 equal $0.5 \mathrm{~h}$ (Figure 8 - dashed lines). As indicated, it takes more than 15 hours for the temperature

4 controller of the extractive column $T C_{1,24}$ to return the temperature to the desired level after this transient.

5 During this time, the distillate purity in the extractive column, $x_{\mathrm{CO} 2}$, becomes unstable and the purity of

6 the bottoms product in the concentrator column reaches 100\%. As already discussed, this poor control

7 performance is because the pressure of the columns with partial condensers are controlled by their vapor

8 distillate flowrates, which vary rapidly during perturbations in the feed. Any variation in the vapor

9 distillate flow upsets the downstream process, causes the valve to saturate, and loses control.

\subsection{Control structure CS II}

11 Good distillation column control prevents rapid pressure changes. A rapid pressure increase decreases

12 vapor flowrates through the trays, which may cause dumping and weeping. A rapid pressure decrease of 13 increases vapor flowrates, which may cause flooding. Any rapid pressure change also presents potential 14 safety and environmental hazards. Controlling the pressure with vapor distillate leads to large and rapid 15 changes in the flowrates of distillate. If the distillate feeds a downstream unit, which as in this case, these 16 large distillate flowrate variabilities represent significant product purity disturbances and upsets. To avoid 17 this issue, condenser heat removal controls pressure and reflux flowrate controls reflux drum level in this 18 system. Additionally, the distillate flowrate remains proportional to the reflux flowrate to maintain a 19 constant reflux ratio.

20 The proposed control structure CS II is shown in Figure 9. Figure 10 exhibits the faceplate of CS II. Note 21 that in the controller faceplate, the " $F C s$ " controller is on cascade mode, indicating that the controller 22 receives its setpoint signal from multiplier " $S / F$ ". Similarly, "FCD2" and "FCD3" are in the cascade 23 mode and receive their setpoints from multipliers " $D_{1} / R_{l}$ " and " $D_{2} / R_{2}$ ", respectively. The following 24 sections describe why these control loops require cascade control. All level controllers are proportional 25 action with a gain of 2. Conventional PI systems control the remaining loops. Relay-feedback test and 
1 Tyreus-Luyben tuning rules provide controller tuning constants in the column temperature loops given in

2 Table 1.

4 The main features of the extractive column control loops are pressure control through condenser heat

5 removal and the reflux drum and bottom level control through the distillate and the bottoms flows,

6 respectively. The column has a total condenser, which eliminates interaction between the reflux drum

$7 \quad$ level and pressure.

8 Similar to CS I structure, stage 24 of the extractive column provides inferential temperature control,

9 which is ultimately controlled by manipulating the reboiler duty. There are two possibilities to determine

10 the second control degree of freedom: (a) holding the reflux ratio constant, or (b) ratioing the reflux

11 flowrate to feed flowrate. When disturbances in feed flowrate occur, both choices are equivalent because

12 all flows ratio directly with throughput. However, when disturbances occur in feed composition, the ratios

13 vary in a different way when the two products are kept at their design specs. The reflux-to-feed ratio

14 structure provides the second control degree of freedom in the following analysis

15 The reflux ratio in the extractive column is 4.61 . When column reflux ratios exceed 3 , it is conventional

16 to control the reflux drum level by regulating the reflux flowrate. However, level control using the reflux

17 prohibits the use of a reflux-to-feed control scheme, which is the effective control structure for feed

18 composition disturbances. On the other hand, manipulating the distillate to control the drum level leads to

19 large alterations in the distillate flowrate, which can upset downstream processes. Assuming that

20 disturbances do not occur rapidly and frequently, the selection of a reflux-to-feed ratio structure handles

21 disturbances more effectively, without rapidly changing the distillate flow rate. 
2 The recovery and concentrator columns have partial condensers, which causes the main difference

3 between the two control structures. CS II differs from CS I structure in the following ways. The rest of the 4 loops are unchanged.

- The reflux flowrate controls the reflux drum level in the solvent recovery and the concentrator columns.

- Condenser heat removal controls pressure in the solvent recovery column and the concentrator columns.

- The reflux ratios remain constant in the solvent recovery and the concentrator columns by reflux flowrate control.

\subsubsection{CS II Results}

In the analysis below, transient analyses of large feed disturbances (20\% alterations in the flowrate of the fresh feed, and $20 \%$ alterations in feed composition) illustrate the performance of the control structure CS II. Figure 11 illustrates all three columns results for a $20 \%$ disturbance in feed flowrate. The dashed lines represent feed stream flowrate decreases $(-20 \%)$ and the solid lines represent increases $(+20 \%)$. These graphs clearly show that the temperatures and product purities are well controlled.

Figure 12 presents all the three columns result for feed composition disturbances. The dashed lines represent ethane feed content increases from 0.46 to 0.51 (mole fraction) with a corresponding decrease in the $\mathrm{CO}_{2}$ feed content from 0.32 to 0.27 . The solid lines represent ethane feed content decreases from 0.46 to 0.41 mole fraction with a corresponding increase in the $\mathrm{CO}_{2}$ feed content from 0.32 to 0.37 . As observed with respect to the federate changes, this scheme provides good control of product purities and temperatures for all the three columns. 
2 The underlying issues illustrated in these specific examples pertain to all partial-condenser column controls. The alternative control system is not as traditional or intuitive and the conventional systems, but its control logic, sensors, and loops are no more complicated or difficult to install. Additionally, the control systems here should be just as effective for any partial condenser column or, for that matter, any distillation column, regardless of whether such columns occur in series and independent of whether they treat azeotropic systems. In these ways, they represent potentially more robust approaches to column control than the conventional approaches.

\section{Conclusions}

Dynamic control using conventional configurations fail to maintain product purities in processes that

11 involve interconnected partial condensers. Specifically, conventional distillation columns control pressure

12 by manipulating vapor distillate flowrate and control reflux drum level should by manipulating condenser

13 heat removal. This control strategy is effective for an isolated distillation column. However, this scheme

14 fails to provide effective control of interconnected columns, specifically columns with interconnected

15 partial condensers. An alternative control scheme controls pressure through condenser heat removal rate 16 and reflux drum level by reflux flow rate. This scheme effectively controls product purities in the face of 17 even large perturbations in feed flowrate and composition. This alternative system is no more 18 complicated than the conventional system and should work on distillation columns of nearly all designs, 19 not just the coupled partial condenser designs for which it is essential.

20 A recently proposed $\mathrm{CO}_{2}$-ethane azeotropic distillation system serves as an example of this control 21 system. The design has one total condenser column and two partial condenser columns. The interaction 22 among the pressure, reflux drum level, and tray temperature control loops make the control of partial 23 condenser columns more complex than total condenser columns. Dynamic analyses indicate that, contrary 24 to expectation, the conventional control structure cannot maintain the purity of the two product streams at 
the desired values. An effective plant-wide control structure based on inferential single-end temperature control is presented for this process. The main features of the control loops of the partial condenser columns in the proposed scheme are reflux drum level control through reflux flowrate, pressure control through heat condenser removal and distillate flowrate ratioed to the reflux flowrate. Transient analyses show that the proposed control structure maintains $\mathrm{CO}_{2}$ and ethane product purities in the face of large disturbances (20\%) in throughput and feed composition. Similar control systems should

\section{Acknowledgements}

8 The information, data, or work presented herein was funded by Sustainable Energy Solutions LLC of

9 Orem, Utah, the Advanced Research Projects Agency - Energy (ARPA-E), U.S. Department of Energy,

10 under Award Number DE-AR0000101, the Climate Change and Emissions Management Corporation

11 (CCEMC) of Alberta, Canada, and the Advanced Conversion Technologies Task Force in Laramie,

12 Wyoming. Sustainable Energy Solutions owns the Cryogenic Carbon Capture (CCC) technology

13 portfolio.

15 [1] E. Ebrahimzadeh, J. Matagi, F. Fazlollahi, L.L. Baxter, Alternative extractive distillation system for

16 CO2-ethane azeotrope separation in enhanced oil recovery processes, Applied Thermal Engineering, 96

17 (2016) 39-47.

18 [2] R.G. Newell, S. Iler, The global energy outlook, in, National Bureau of Economic Research, 2013. [3] B. Bazooyar, N. Hallajbashi, A. Shariati, A. Ghorbani, An Investigation of the Effect of Input Air Upon Combustion Performance and Emissions of Biodiesel and Diesel Fuel in an Experimental Boiler, Energy Sources, Part A: Recovery, Utilization, and Environmental Effects, 36 (2014) 383-392.

[4] B. Bazooyar, A. Shariati, A Comparison of the Emission and Thermal Capacity of Methyl Ester of Corn Oil with Diesel in an Experimental Boiler, Energy Sources, Part A: Recovery, Utilization, and Environmental Effects, 35 (2013) 1618-1628.

[5] D. Elliot, W.R. Qualls, S. Huang, J.J. Chen, R.J. Lee, J. Yao, Y. Zhang, Benefits of integrating NGL extraction and LNG liquefaction technology, in: 2005 AIChE Spring National Meeting, Conference Proceedings, 2005, pp. 1943-1958.

[6] S.M. Safdarnejad, J.D. Hedengren, L.L. Baxter, Plant-level dynamic optimization of Cryogenic Carbon Capture with conventional and renewable power sources, Applied Energy, 149 (2015) 354-366. [7] R.C. Jensen MJ, Bergerson D, Hoeger CD, Frankman DJ, Bence CS, Baxter LL Prediction and validation of external cooling loop cryogenic carbon capture (CCC ECL) for full-scale coal-fired power plant retrofit, Int J Greenhouse Gas Control, 42 (2015) 200-212.

[8] S.M. Safdarnejad, L. Kennington, L.L. Baxter, J.D. Hedengren, Investigating the impact of Cryogenic

34 Carbon Capture on power plant performance. 
[9] B.A. Fazlollahi F, Ebrahimzadeh E, Baxter LL. , Design and analysis of the natural gas liquefaction optimization process- Energy Storage of Cryogenic Carbon Capture (CCC-ES), Energy, in press (2015).

[10] E. Ebrahimzadeh, P. Wilding, D. Frankman, F. Fazlollahi, L.L. Baxter, Theoretical and experimental analysis of dynamic plate heat exchanger: Non-retrofit configuration, Applied Thermal Engineering, 93 (2016) 1006-1019.

[11] B. ZareNezhad, N. Hosseinpour, An extractive distillation technique for producing CO2 enriched injection gas in enhanced oil recovery (EOR) fields, Energy Conversion and Management, 50 (2009) 1491-1496.

[12] M.F. Doherty, M.F. Malone, Conceptual design of distillation systems, McGraw-Hill Science/Engineering/Math, 2001.

[13] J. Stichlmair, J.R. Fair, Distillation: principles and practices, Vch Verlagsgesellschaft Mbh, 1998.

[14] J.H. Hong, R. Kobayashi, To break an azeotrope. 1. The use of n-pentane to break the carbon dioxide-ethane azeotrope, for carbon dioxide EOR gas processing, Industrial \& Engineering Chemistry Process Design and Development, 25 (1986) 736-741.

[15] C.E. Torres-Ortega, J.G. Segovia-Hernández, F.I. Gómez-Castro, S. Hernández, A. BonillaPetriciolet, B.-G. Rong, M. Errico, Design, optimization and controllability of an alternative process based on extractive distillation for an ethane-carbon dioxide mixture, Chemical Engineering and Processing: Process Intensification, 74 (2013) 55-68.

[16] F. Lastari, V. Pareek, M. Trebble, M.O. Tade, D. Chinn, N.C. Tsai, K.I. Chan, Extractive distillation for CO2-ethane azeotrope separation, Chemical Engineering and Processing: Process Intensification, 52 (2012) 155-161.

[17] Y. Tavan, S. Shahhosseini, S.H. Hosseini, Feed-splitting technique in the extractive distillation of CO2-ethane azeotropic process, Separation and Purification Technology, 122 (2014) 47-53.

[18] R. Hasanvandian, Y. Tavan, Techno-Economic Analysis of the Carbon Dioxide (CO2)-Ethane Azeotrope Separation for Natural Gas Processes, Energy Technology, 3 (2015) 570-578.

[19] Y. Tavan, S. Shahhosseini, S.H. Hosseini, Design and simulation of ethane recovery process in an extractive dividing wall column, Journal of Cleaner Production, 72 (2014) 222-229.

[20] Y. Tavan, S.H. Hosseini, A novel application of reactive absorption to break the CO2-ethane azeotrope with low energy requirement, Energy Conversion and Management, 75 (2013) 407-417. [21] Y. Tavan, A. Tavan, Performance of conventional gas sweetening process to remove CO2 in presence of azeotrope, Journal of CO2 Utilization, 5 (2014) 24-32.

[22] Y. Tavan, A note on use of the CO2-ethane azeotrope as new feed of reforming process using mathematical modeling, Journal of Natural Gas Science and Engineering, 21 (2014) 275-282.

[23] A.A. Kiss, R.M. Ignat, Innovative single step bioethanol dehydration in an extractive dividing-wall column, Separation and Purification Technology, 98 (2012) 290-297.

[24] W.L. Luyben, Alternative Control Structures for Distillation Columns with Partial Condensers, Industrial \& Engineering Chemistry Research, 43 (2004) 6416-6429.

[25] W.L. Luyben, Control of the maximum-boiling acetone/chloroform azeotropic distillation system, Industrial \& Engineering Chemistry Research, 47 (2008) 6140-6149.

[26] W.L. Luyben, Effect of solvent on controllability in extractive distillation, Industrial \& Engineering Chemistry Research, 47 (2008) 4425-4439.

[27] I.-L. Chien, K.-L. Zeng, H.-Y. Chao, Design and control of a complete heterogeneous azeotropic distillation column system, Industrial \& Engineering Chemistry Research, 43 (2004) 2160-2174.

[28] L.M. Rueda, T.F. Edgar, R.B. Eldridge, A novel control methodology for a pilot plant azeotropic distillation column, Industrial \& Engineering Chemistry Research, 45 (2006) 8361-8372.

[29] W.L. Luyben, Plantwide control of an isopropyl alcohol dehydration process, Aiche Journal, 52 (2006) 2290-2296.

[30] S. Arifin, I.-L. Chien, Design and control of an isopropyl alcohol dehydration process via extractive distillation using dimethyl sulfoxide as an entrainer, Industrial \& Engineering Chemistry Research, 47 (2008) 790-803. 
1 [31] W.L. Luyben, Design and control of a fully heat-integrated pressure-swing azeotropic distillation 2 system, Industrial \& Engineering Chemistry Research, 47 (2008) 2681-2695.

3 [32] W.L. Luyben, Comparison of extractive distillation and pressure-swing distillation for acetone4 methanol separation, Industrial \& Engineering Chemistry Research, 47 (2008) 2696-2707.

5 [33] W.L. Luyben, Control of the Heterogeneous Azeotropic n-Butanol/Water Distillation System, 6 Energy \& Fuels, 22 (2008) 4249-4258.

7 [34] W.L. Luyben, Control of a column/pervaporation process for separating the ethanol/water azeotrope, 8 Industrial \& Engineering Chemistry Research, 48 (2009) 3484-3495.

9 [35] Y.C. Wu, I.-L. Chien, W.L. Luyben, Two-stripper/decanter flowsheet for methanol recovery in the

10 TAME reactive-distillation process, Industrial \& Engineering Chemistry Research, 48 (2009) 105321110540.

12 [36] Y.-C. Wu, I.-L. Chien, Design and control of heterogeneous azeotropic column system for the 13 separation of pyridine and water, Industrial \& Engineering Chemistry Research, 48 (2009) 10564-10576.

14 [37] K.-Y. Hsu, Y.-C. Hsiao, I.-L. Chien, Design and control of dimethyl carbonate- methanol separation 15 via extractive distillation in the dimethyl carbonate reactive-distillation process, Industrial \& Engineering 16 Chemistry Research, 49 (2009) 735-749.

17 [38] J.R. Phimister, W.D. Seider, Semicontinuous, pressure-swing distillation, Industrial \& Engineering 18 Chemistry Research, 39 (2000) 122-130.

19 [39] J.R. Phimister, W.D. Seider, Semicontinuous, middle-vessel, extractive distillation, Computers \& 20 Chemical Engineering, 24 (2000) 879-885.

21 [40] P.S. Buckley, Techniques of process control, Wiley, 1964.

22 [41] F. Skinskey, Distillation control: For productivity and energy conservation, (1984).

23 [42] A.E.S. Hori, B.S. Skogestad, Control structure selection of a deethanizer column with partial 24 condenser, in: Proceedings of European Congress of Chemical Engineering (ECCE-6), 2007, pp. 16-20. 25 [43] W.L. Luyben, Realistic Models for Distillation Columns with Partial Condensers Producing Both 26 Liquid and Vapor Products, Industrial \& Engineering Chemistry Research, 51 (2012) 8334-8339.

27 [44] V.G. Grassi II, Process design and control of extractive distillation, in: Practical distillation control, 28 Springer, 1993, pp. 370-404. 
Table 1. Controller Tuning Parameters

\begin{tabular}{|l|l|l|l|}
\hline & \multicolumn{1}{|c|}{$T_{C_{1,24}}$} & \multicolumn{1}{c|}{$T_{C_{2,24}}$} & \multicolumn{1}{c|}{$T_{C_{3,22}}$} \\
\hline controlled variable & $\begin{array}{l}\text { stage 24 temperature in } \\
\text { extractive column }\end{array}$ & $\begin{array}{l}\text { stage 24 temperature in } \\
\text { extractive column }\end{array}$ & $\begin{array}{l}\text { stage 22 temperature in } \\
\text { extractive column }\end{array}$ \\
\hline manipulated variable & reboiler heat input $Q_{b, 1}$ & reboiler heat input $Q_{b, 2}$ & reboiler heat input $Q_{b, 3}$ \\
\hline setpoint & $271.86 \mathrm{~K}$ & $334.72 \mathrm{~K}$ & $270.30 \mathrm{~K}$ \\
\hline transmitter range & $240-340 \mathrm{~K}$ & $300-400 \mathrm{~K}$ & $240-340 \mathrm{~K}$ \\
\hline OP & $15.12 \mathrm{MW}$ & $90.47 \mathrm{MW}$ & $21.32 \mathrm{MW}$ \\
\hline OP range & 0 to $30.24 \mathrm{MW}$ & 0 to $180.95 \mathrm{MW}$ & 0 to $42.66 \mathrm{MW}$ \\
\hline dead-time & $1 \mathrm{~min}$ & $1 \mathrm{~min}$ & $1 \mathrm{~min}$ \\
\hline$K_{C}$ & 3.71 & 1.8 & 3.8 \\
\hline$\tau_{I}$ & 9.8 & 10.7 & 7.2 \\
\hline
\end{tabular}




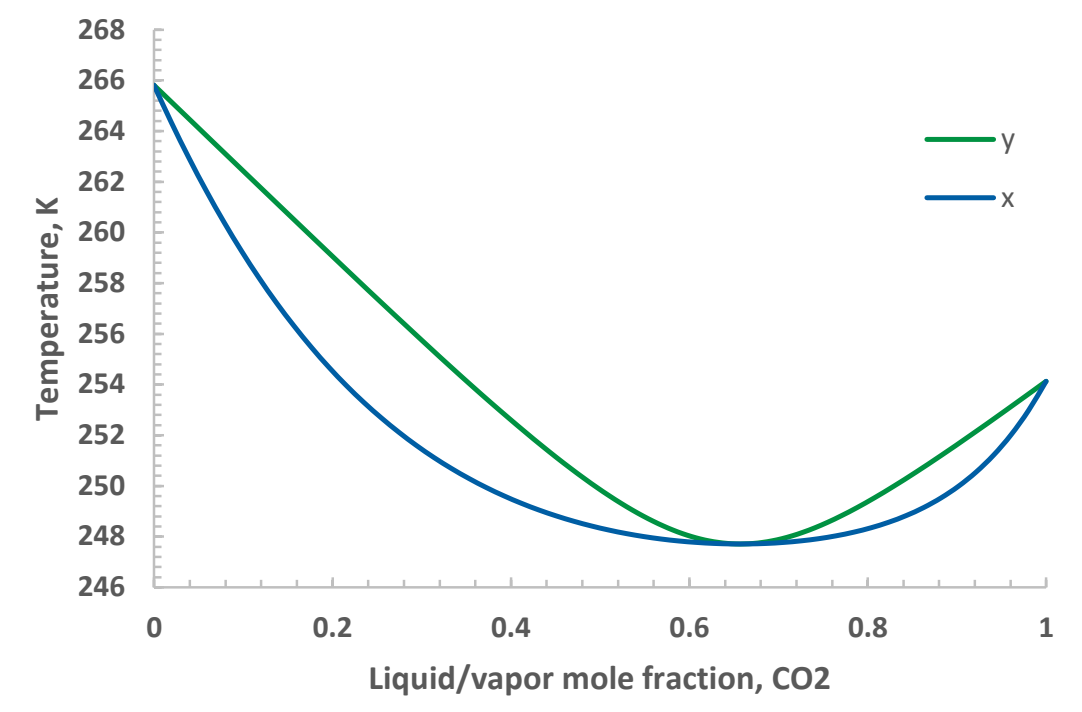

Figure $1 . \mathrm{CO}_{2}$-ethane at 20 bar. 
(a)

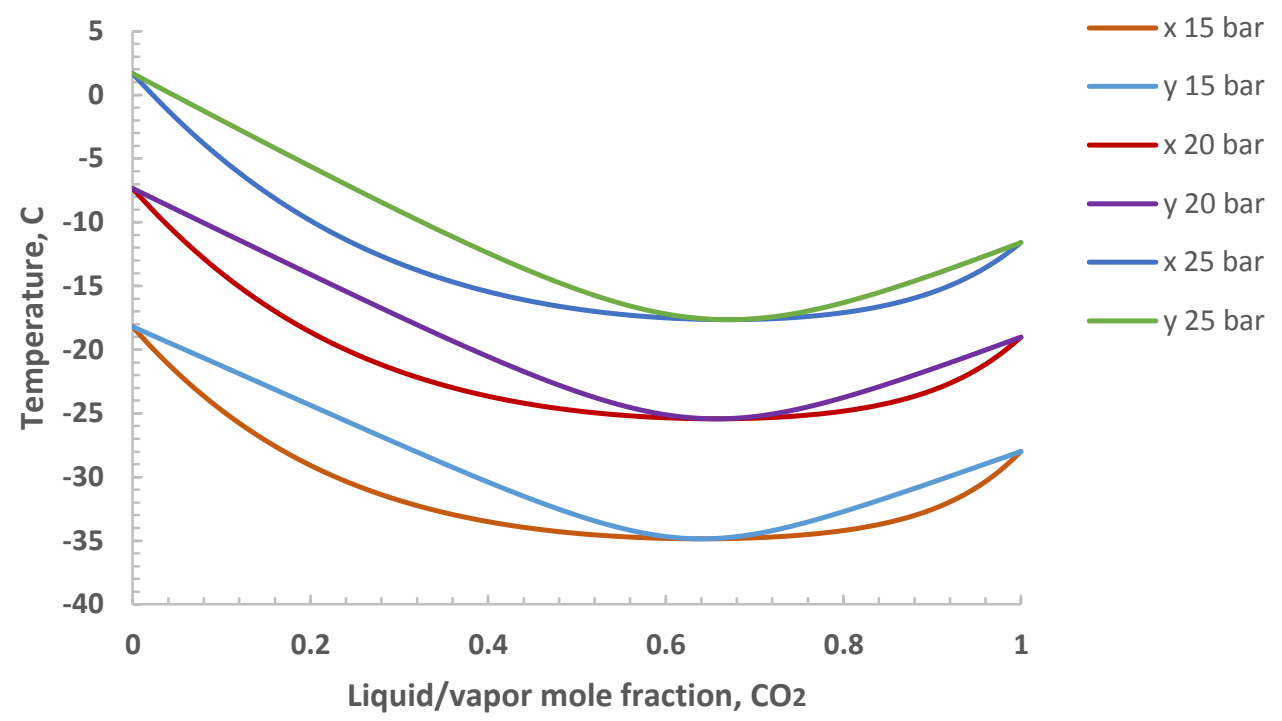

(b)

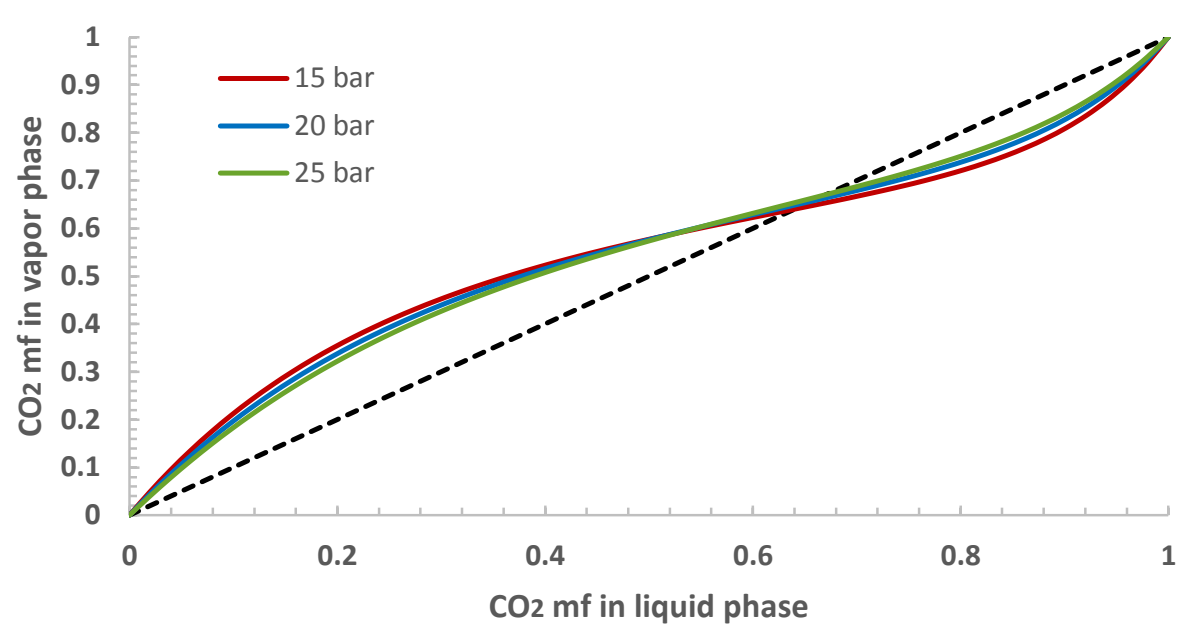

Figure 2. T-xy (a) and $x y$ diagram (b) of the azeotrope mixture of ethane- $\mathrm{CO}_{2}$ over a range of pressures and compositions. 
(a)

$40 \%$ CO2, $45 \%$ C2, $15 \%$ NC4 - $30 \%$ CO2, 35 \% C2, 35\% NC4

$-25 \%$ CO2, $20 \%$ C2, 55\% NC4 - $50 \%$ CO2, 50\% C2

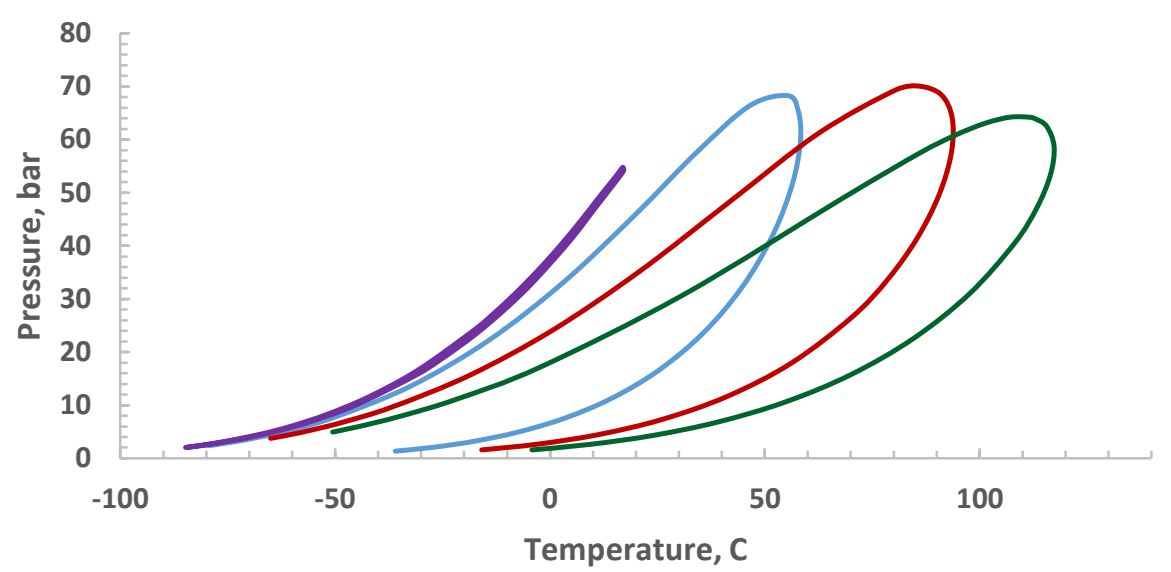




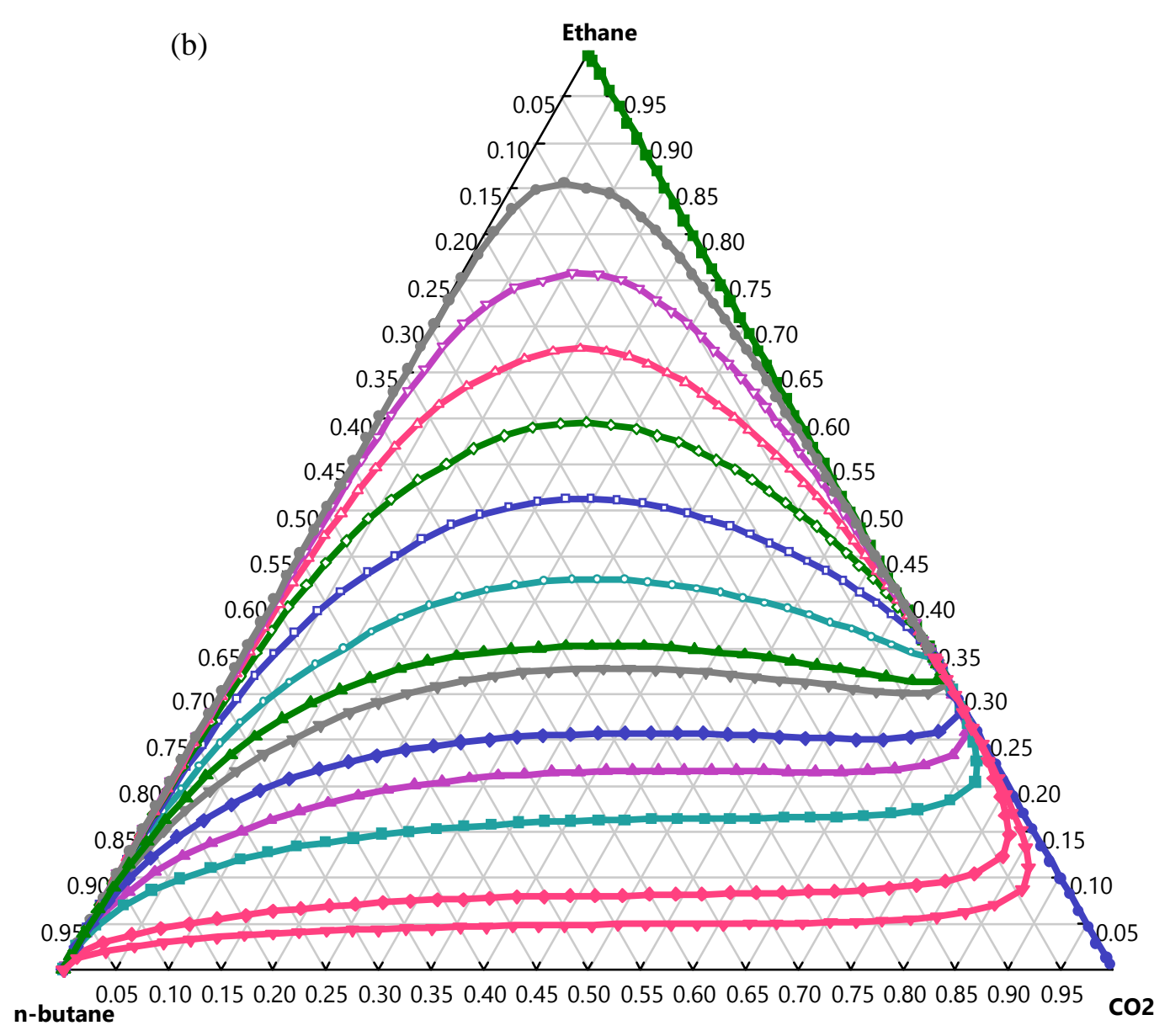

Figure 3. phase envelope (a) and residue curve map (b) for the mixture of ethane, carbon dioxide and n-butane at 20 bar. 


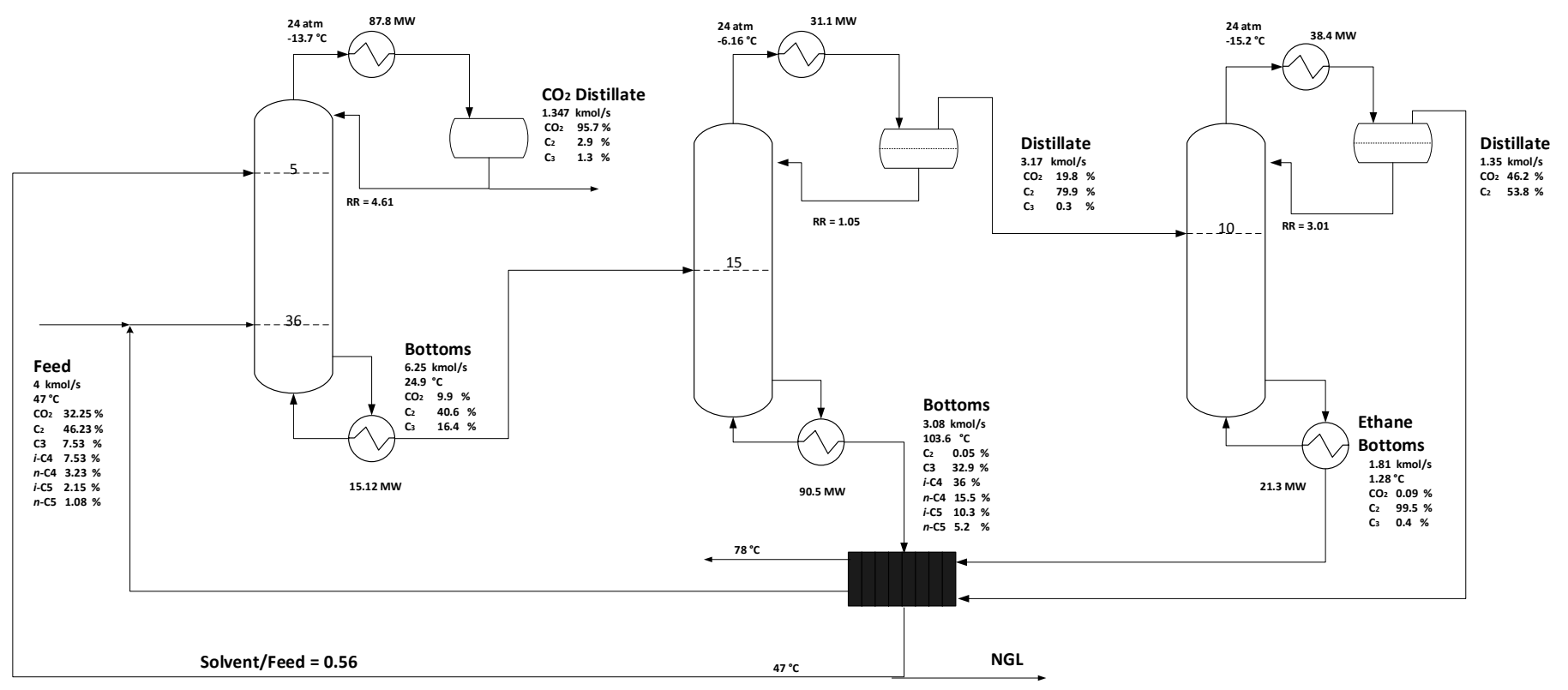

Figure 4. The flowsheet for the proposed $\mathrm{CO}_{2}$-ethane azeotrope separation. 


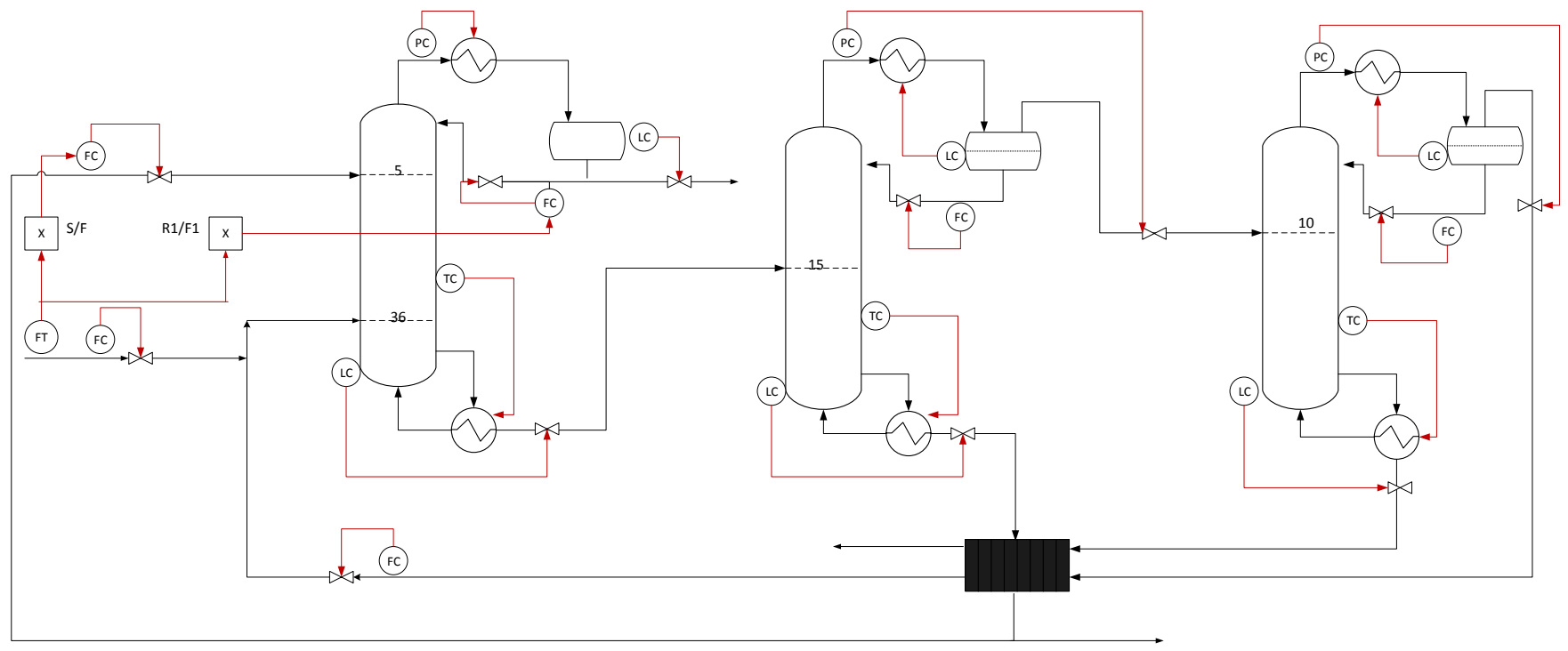

Figure 5. The conventional control structure (CS I) of the new extractive distillation process. 


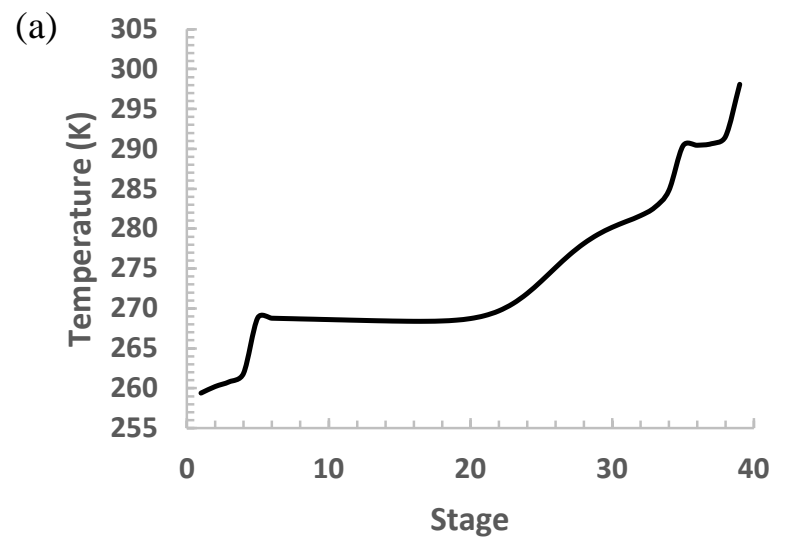

(c)

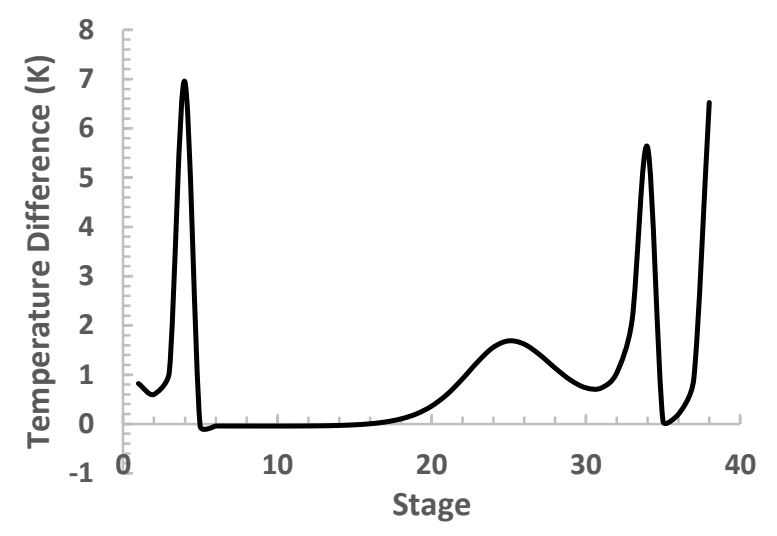

(b)

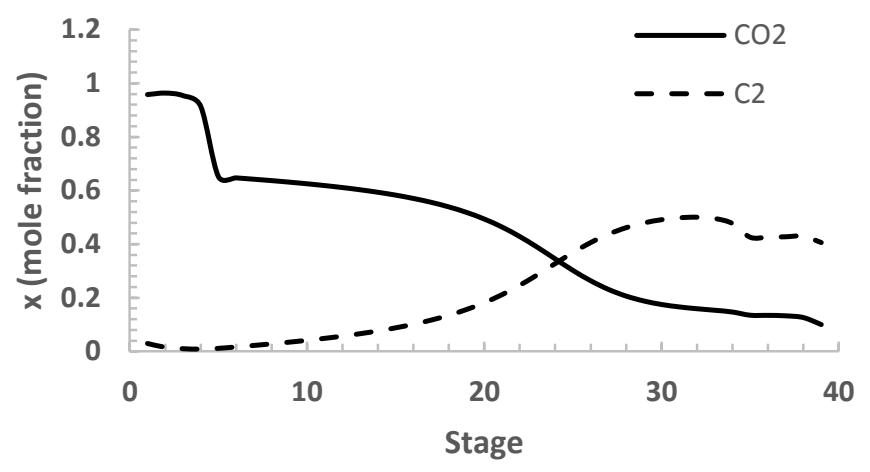

(d)

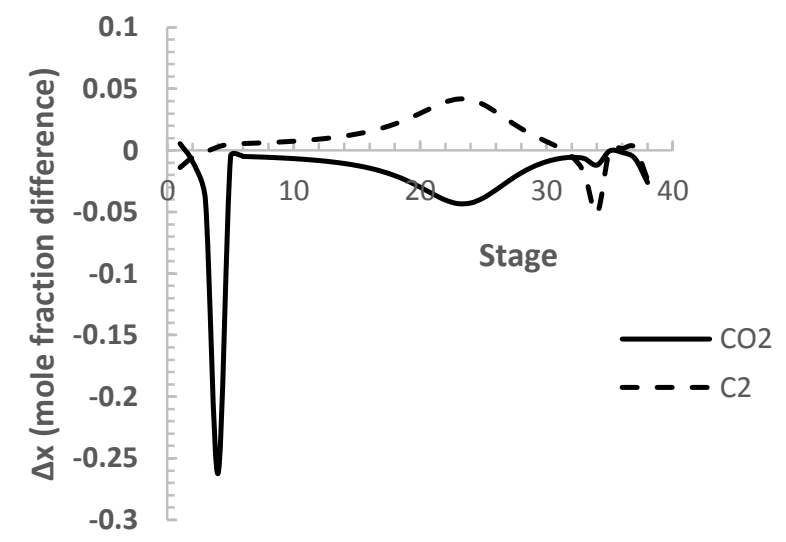

Figure 6. Temperature profile (a), composition profile, (c) temperature slopes and composition slopes (d) in the extractive column. 
(a)

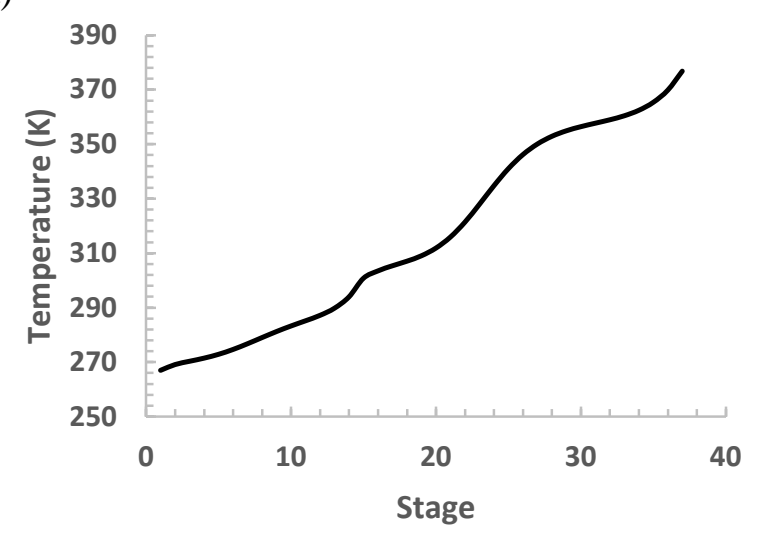

(b)

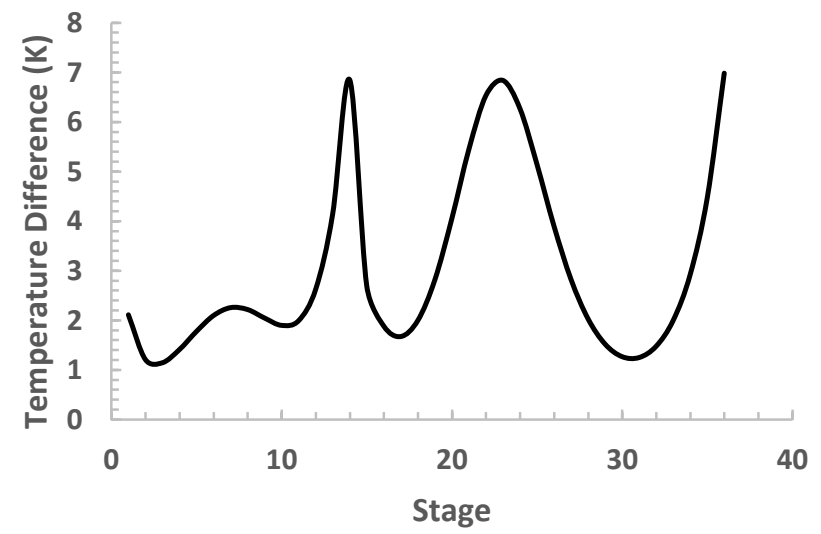

(c)

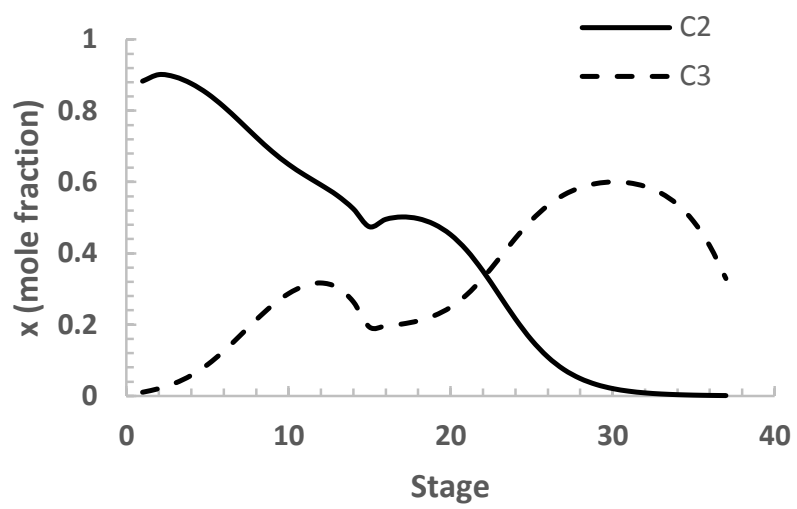

(d)

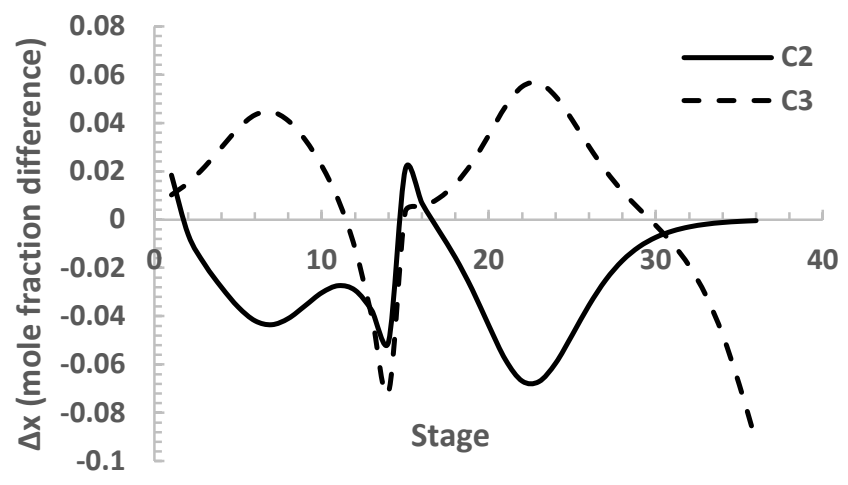

Figure 7. Temperature profile (a), composition profile, (c) temperature slopes and composition slopes (d) in the solvent recovery column. 
(a)
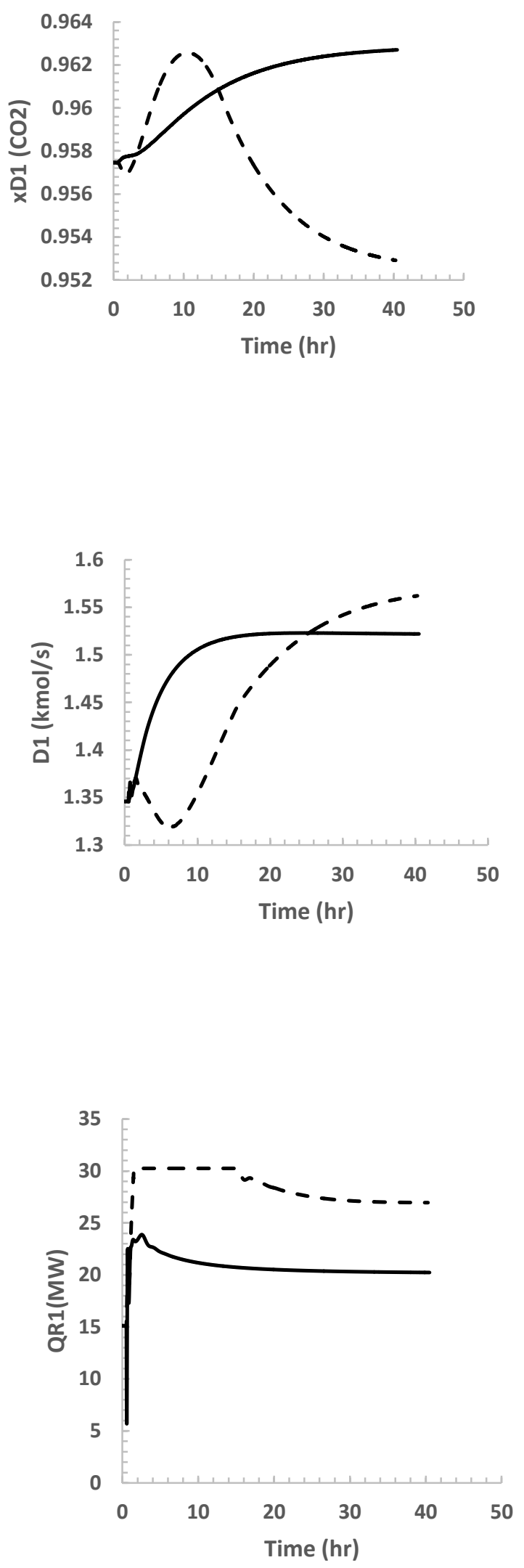
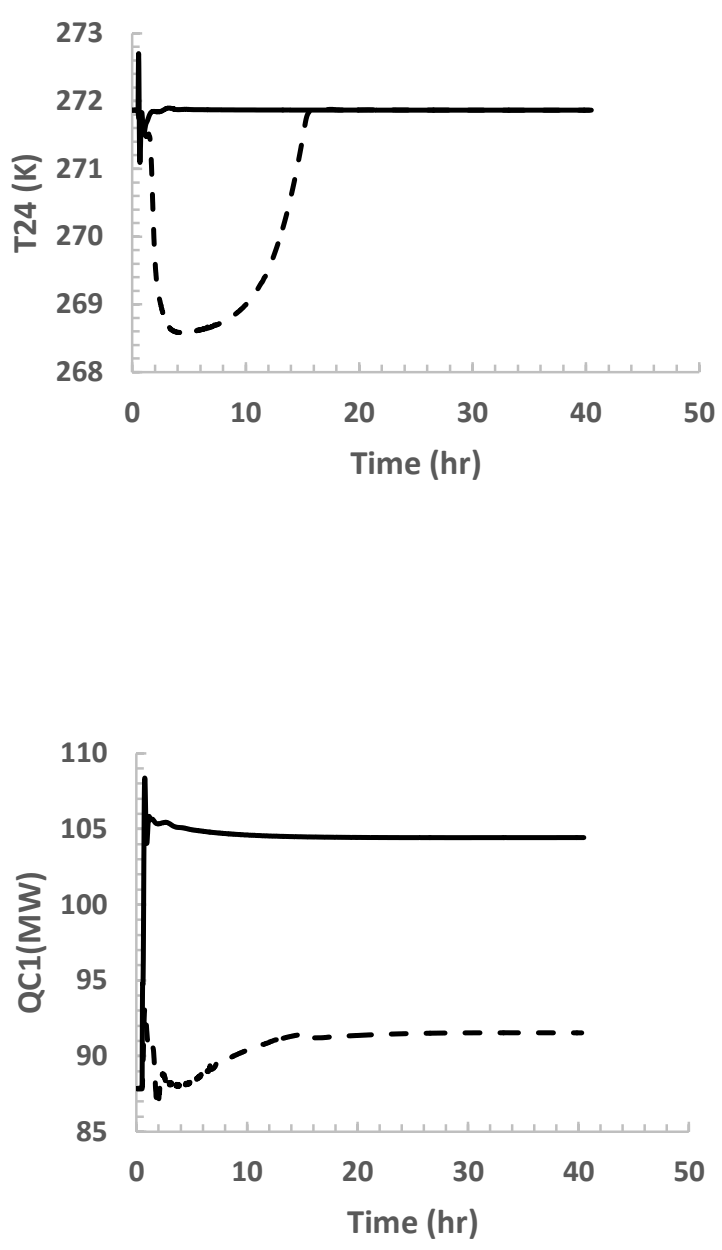
(b)
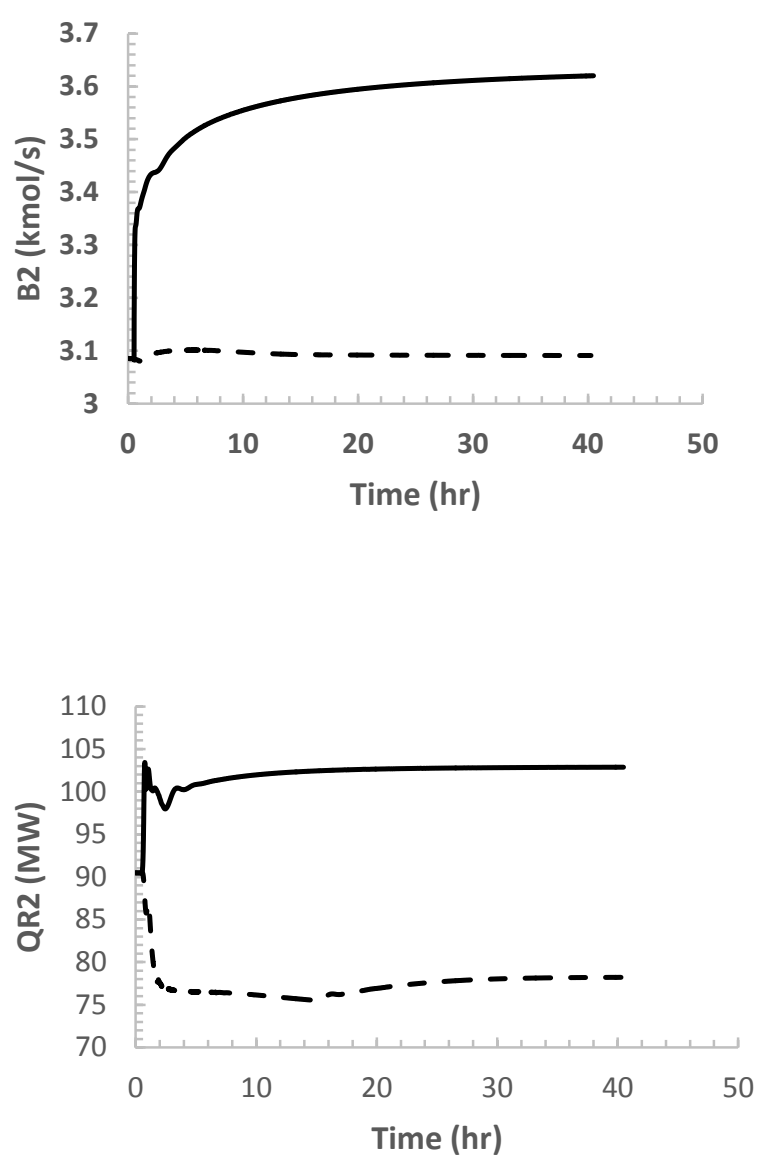
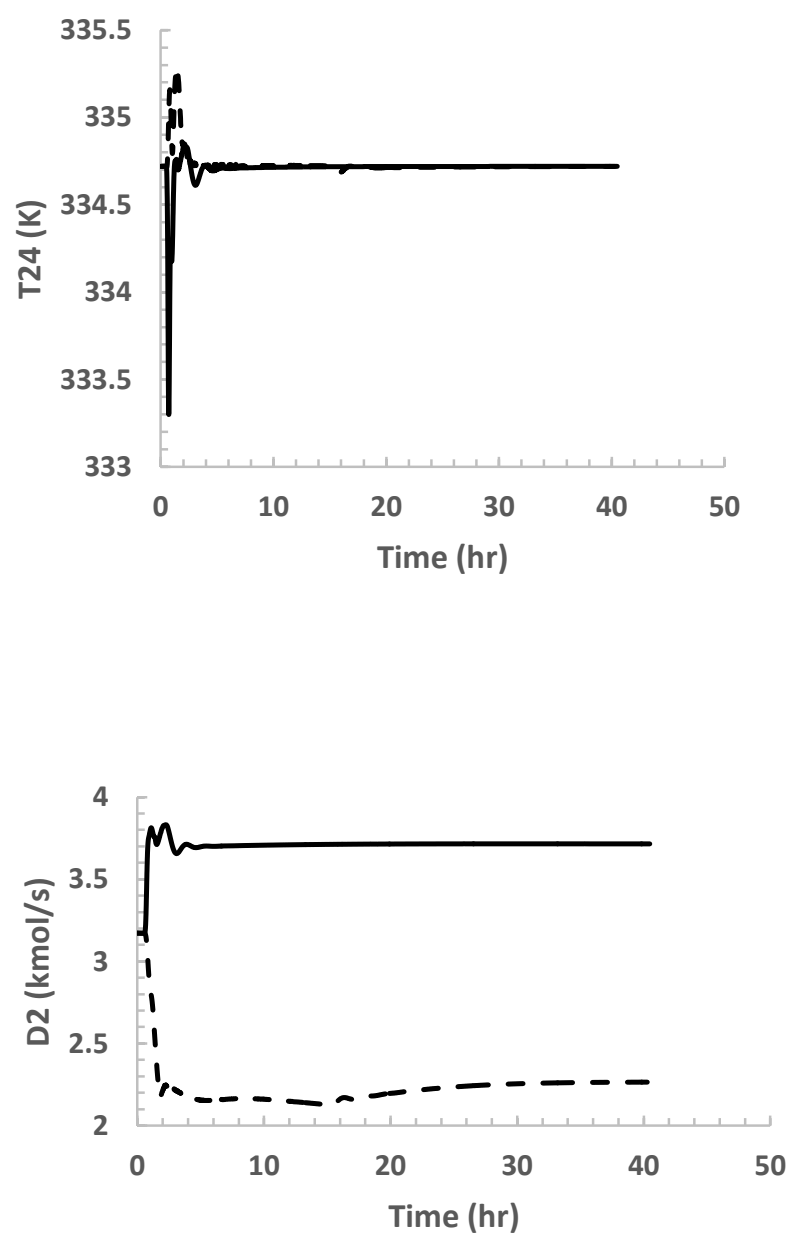
(c)
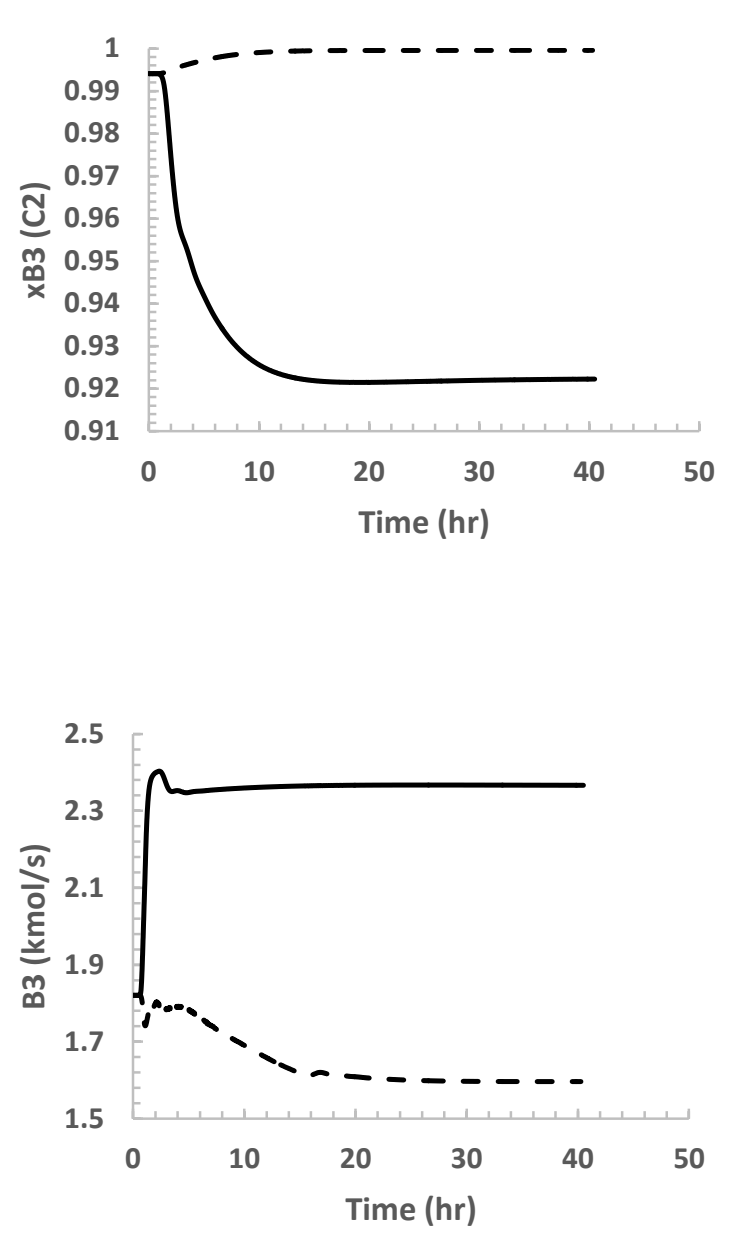
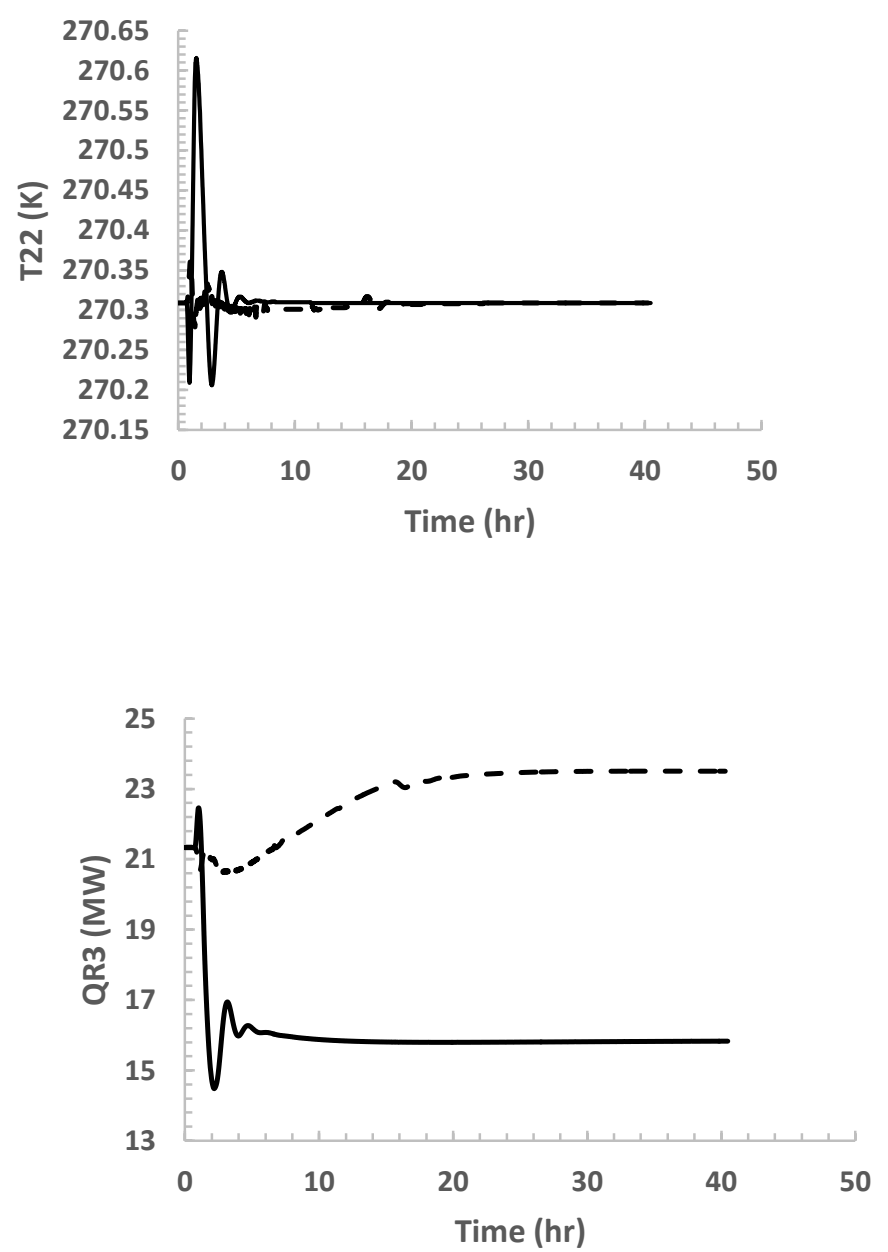

Figure 8. (a) Extractive column, (b) Recovery column, and (c) Concentrator column responses in the face of fresh feed flowrate and composition disturbances: Solid lines are for the case of $+20 \%$ increase in feed flowrate, and dashed lines are for the case of $-5 \%$ decrease in ethane composition and $+5 \%$ increase in $\mathrm{CO}_{2}$ composition in the fresh feed content. 


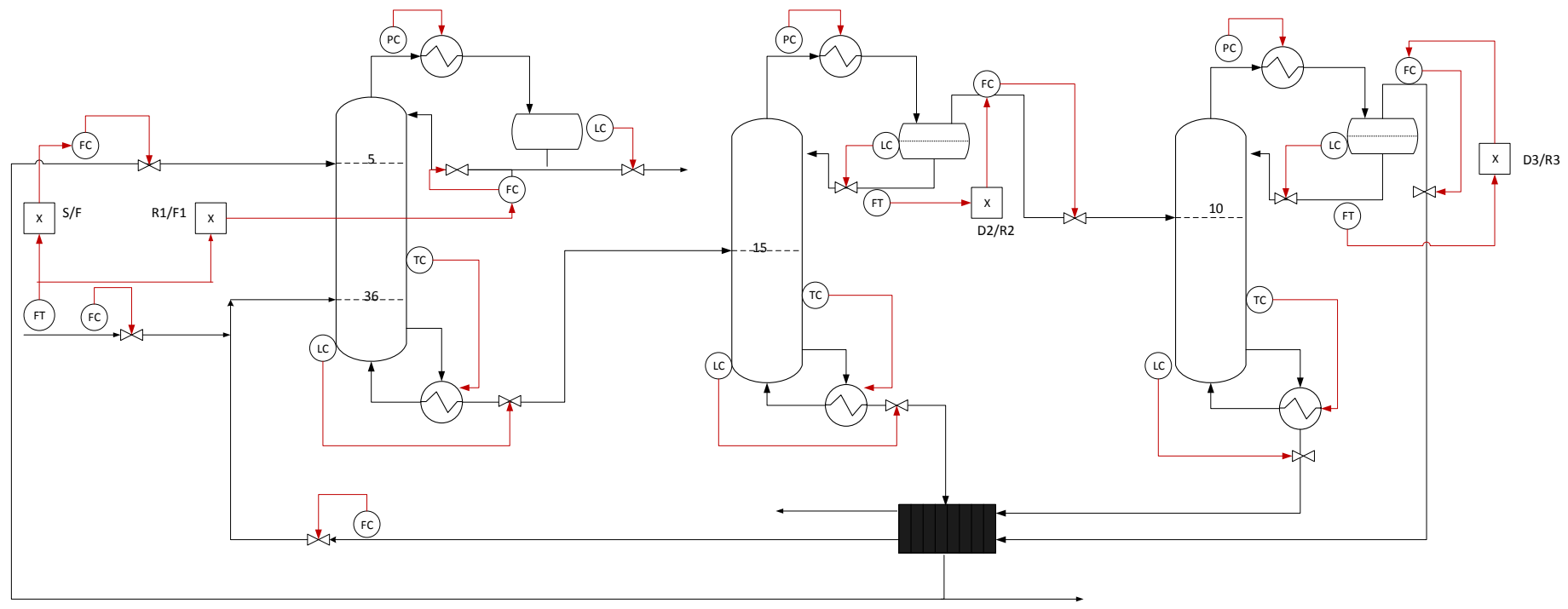

Figure 9. The proposed control structure (CS II) of the new extractive distillation process. 


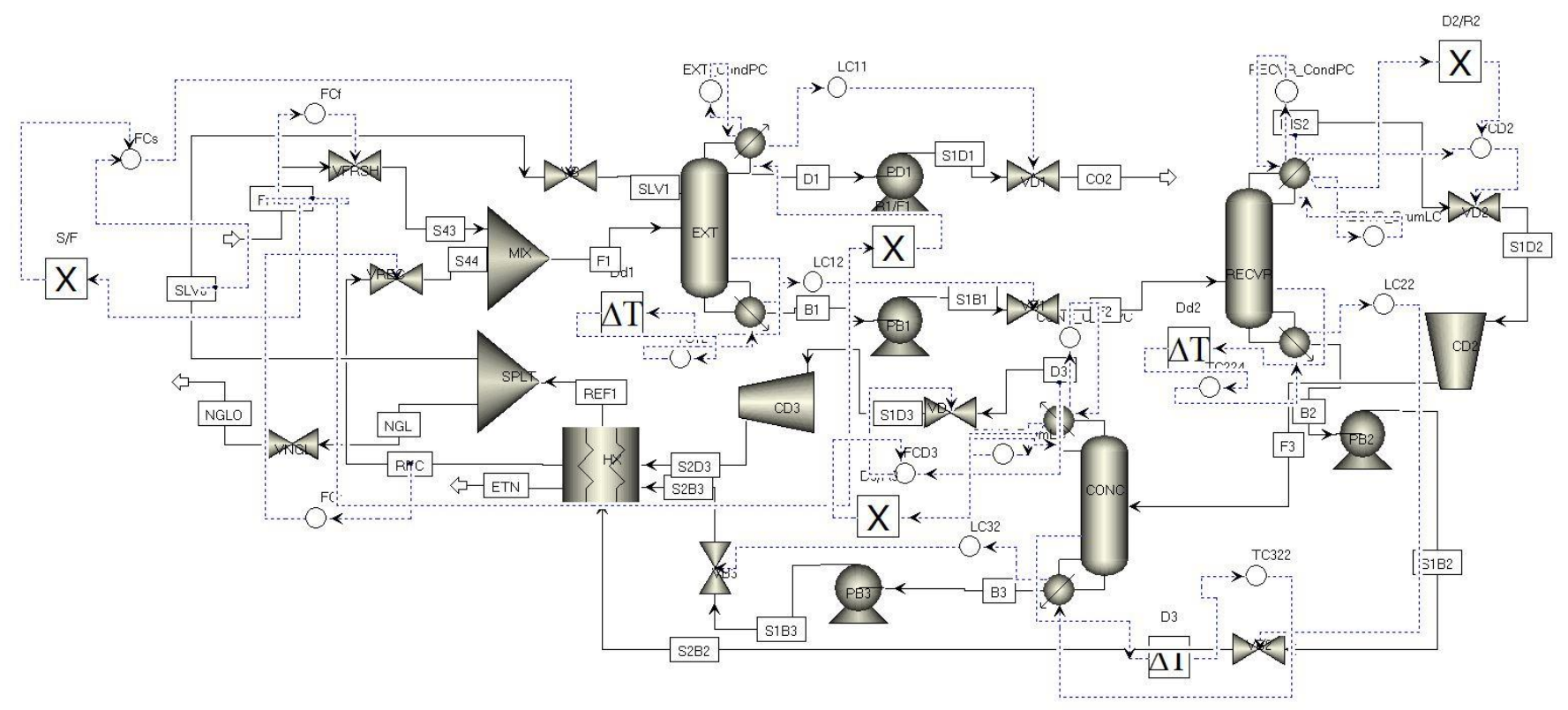

\begin{tabular}{|c|c|c|c|c|c|c|c|c|c|c|c|c|c|c|}
\hline [D] LC11 & & 回 $\mathbb{E}$ & [Di $\mathrm{LC} 12$ & & 回 $\mathbb{E}$ & (10) LC22 & & 回 $\Sigma_{3}$ & (iv) LC32 & & 回 $E_{3}$ & (1) FCf & & 回 23 \\
\hline 然 & $\%$ & 키체 & - & $\%$ & $\exists=\sqrt{0}$ & \begin{tabular}{|l|l|}
2 \\
\end{tabular} & $\%$ & 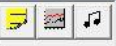 & - कo 3 & $\%$ & 쾨메 $\mathrm{s}$ & $\mid$\begin{tabular}{l|l}
2 \\
2
\end{tabular} & $\%$ & 키쵸 $\curvearrowleft$ \\
\hline SPI & & 15.625 & SP & & 8.45 & SPI & & 16.45 & SP & & 10.325 & SP & & 4. \\
\hline PV & & 15.625 & PV & & 8.45 & $\mathrm{PV}$ & & 16.45 & $\mathrm{PV}$ & & 10.325 & PV & & 4.0 \\
\hline $\mathrm{OP}$ & & 50.0 & OP & & 50.0 & $\mathrm{OP}$ & & 50.0 & $\mathrm{OP}$ & & 50.0 & $\mathrm{OP}$ & & 50.0 \\
\hline (i) FCs & 0 & 回 23 & (Di) $\mathrm{FCr}$ & 들 & 回 $\Sigma_{3}$ & (1) TC124 & 든 & 回 23 & [iv TC224 & & 回 $\Sigma$ & [iv TC322 & 믕 & \begin{tabular}{|l|l|}
1 & 23 \\
\end{tabular} \\
\hline$=15$ & $\%$ & 키체 $\mathrm{s}$ & \% & $\%$ & $\exists \mid$ 或 & $\Rightarrow$ & $\%$ & $\exists=0$ & is & $\%$ & 키체 & 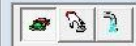 & $\%$ & 키에 \\
\hline $\mathrm{SP}$ & & 2.2526 & SP & & 1.3498 & $\mathrm{sP}$ & & 271.8668 & SP & & 334.7201 & SP & & 270.3088 \\
\hline $\mathrm{PV}$ & & 2.2526 & & & 1.3498 & $\mathrm{PV}$ & & 271.8668 & $\mathrm{PV}$ & & 334.7201 & PV & & 270.3088 \\
\hline OP & & 50.0 & OP & & 50.0 & $\mathrm{OP}$ & & $\longdiv { 1 5 1 2 0 0 0 0 . 0 }$ & $\mathrm{OP}$ & & 90475437.2 & $\mathrm{OP}$ & & 21332728.9 \\
\hline [iv RECVP & 0 & 回 23 & (1) RECVR_D... & C & 回 $E_{3}$ & (10) $\mathrm{FCD} 2$ & & (a) 23 & (iv) CONC_C... & 0 & (1) 23 & (i) CONC_Dr... & . & 回 \\
\hline st & $\%$ & $\exists=0$ & - की & $\%$ & 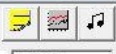 & $\Delta \sqrt{3}$ & $\%$ & ज्ञ|⿴囗玉 & की & $\%$ & 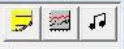 & 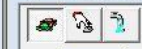 & $\%$ & 키에 \\
\hline SP & & 2431800. & SP & & 14.575 & SP & & 3.1709 & SP & & 2431797.241 & $\mathrm{SP}$ & & 13.625 \\
\hline $\mathrm{PV}$ & & 2431800.0 & $\mathrm{PV}$ & & 14.575 & $\mathrm{PV}$ & & 3.1709 & $\mathrm{PV}$ & & 2431797.241 & PV & & 13.625 \\
\hline OP & & -31132727.2 & OP & & 105.6492 & $\mathrm{OP}$ & & 50.0 & OP & & -38481616.8 & $\mathrm{OP}$ & & 141.6349 \\
\hline [iv $\mathrm{FCD}_{3}$ & 므 & 回 Es & & & & & & & & & & & & \\
\hline 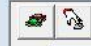 & $\%$ & 키세 $\mathrm{s}$ & & & & & & & & & & & & \\
\hline SP & & 1.3498 & & & & & & & & & & & & \\
\hline $\mathrm{PV}$ & & 1.3498 & & & & & & & & & & & & \\
\hline $\mathrm{OP}$ & & 50.0 & & & & & & & & & & & & \\
\hline
\end{tabular}

Figure 10. Control structure CSII and the faceplate. 
(a)
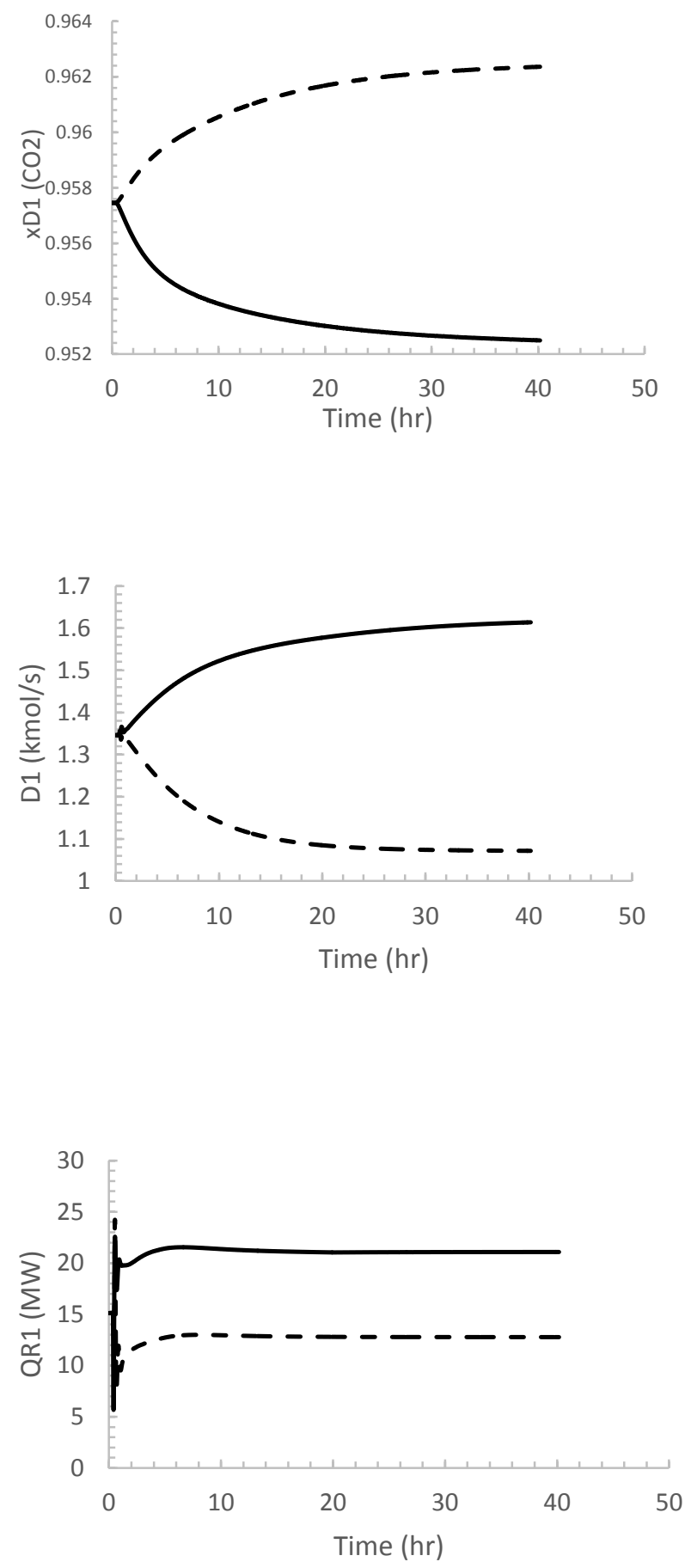
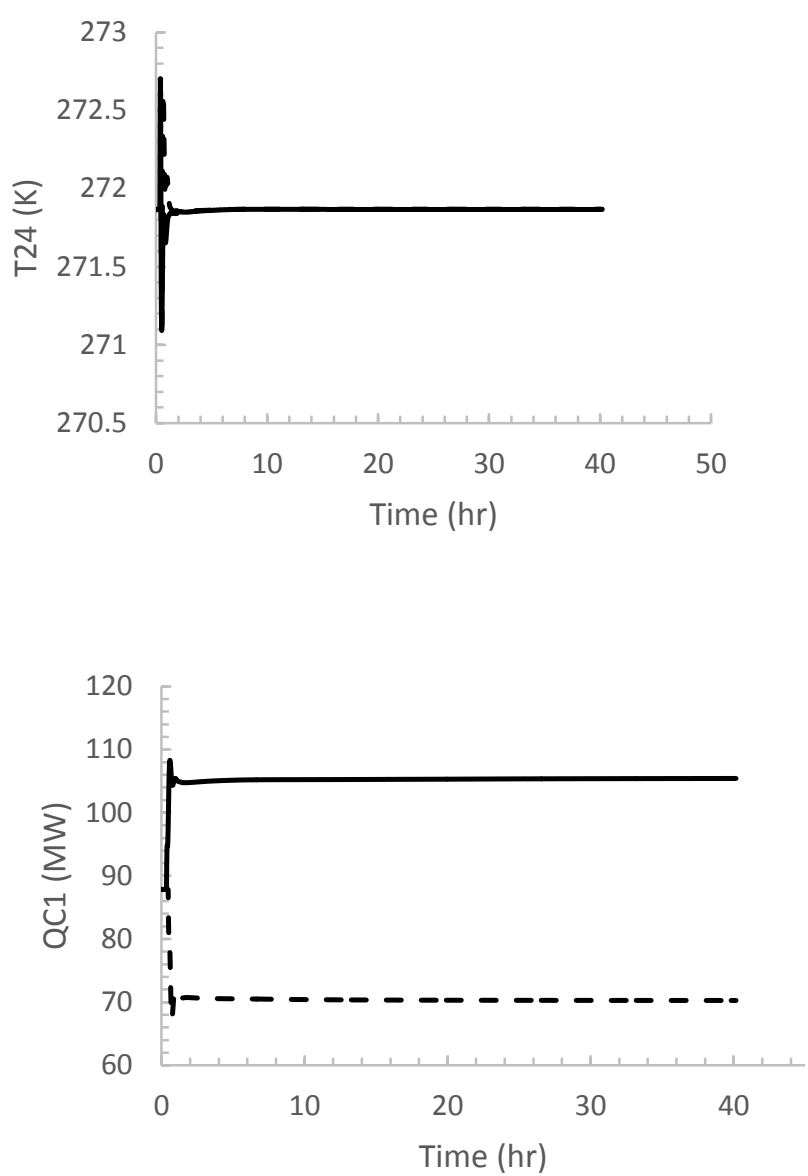
(b)
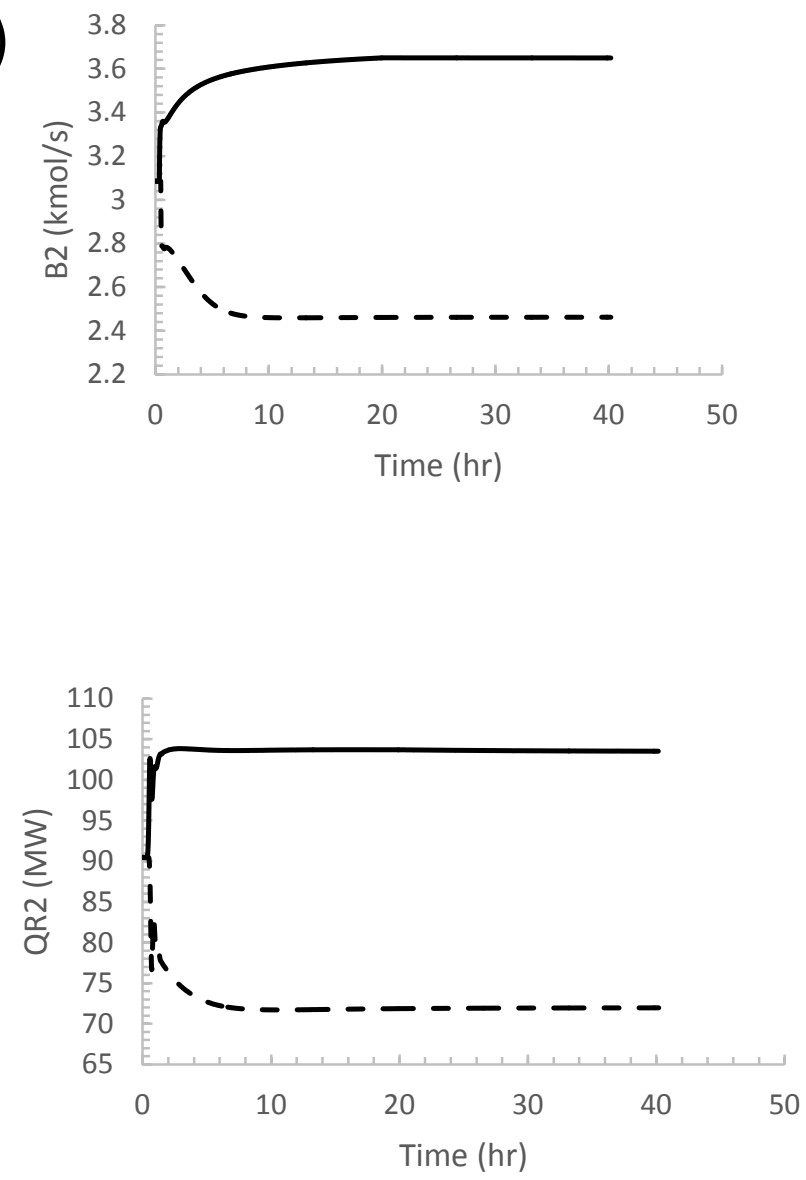
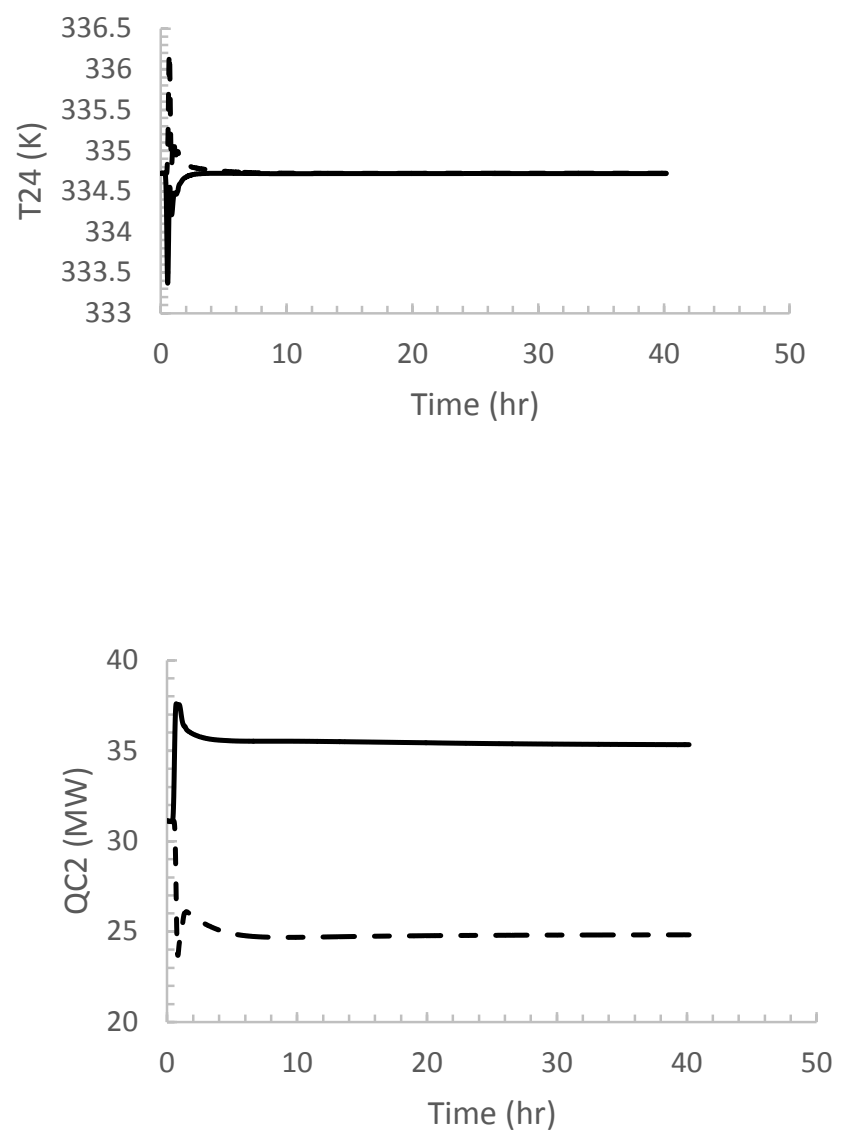
(c)
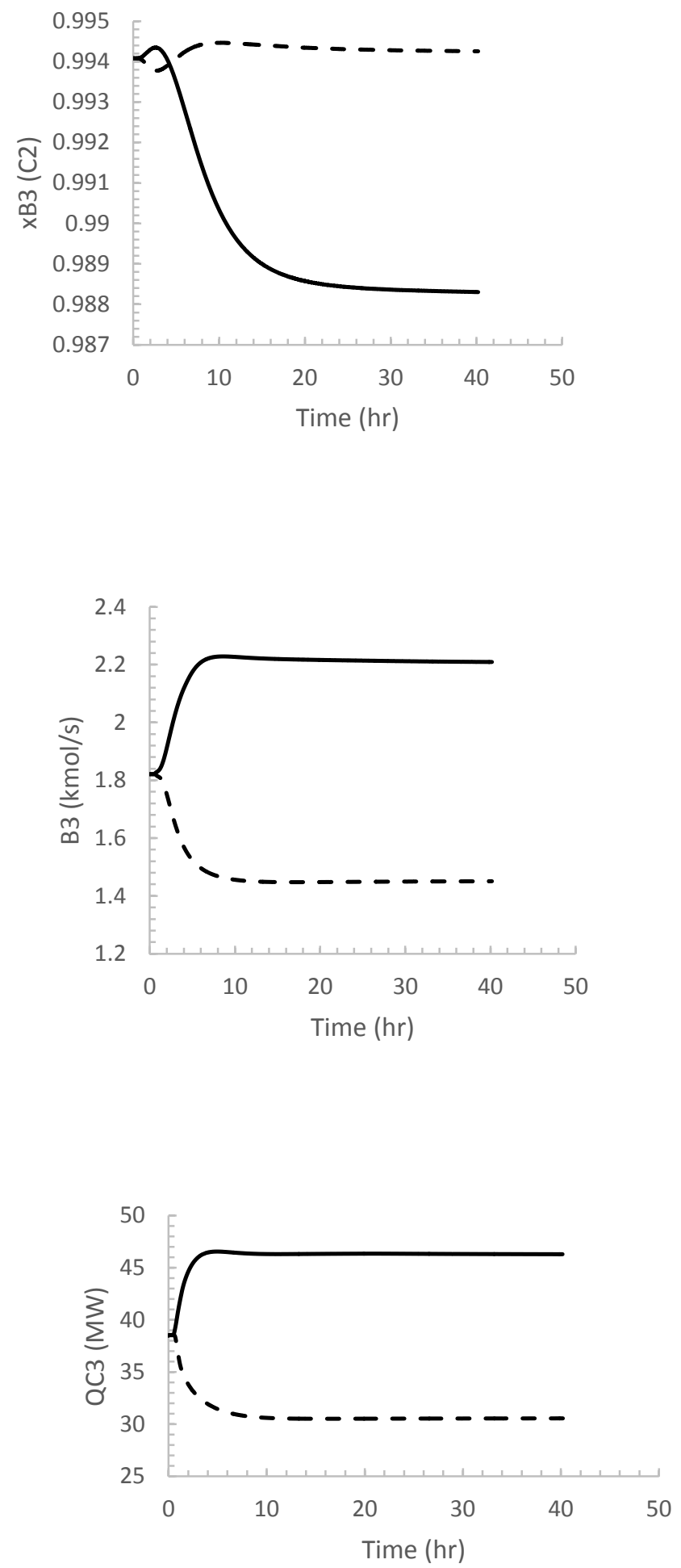
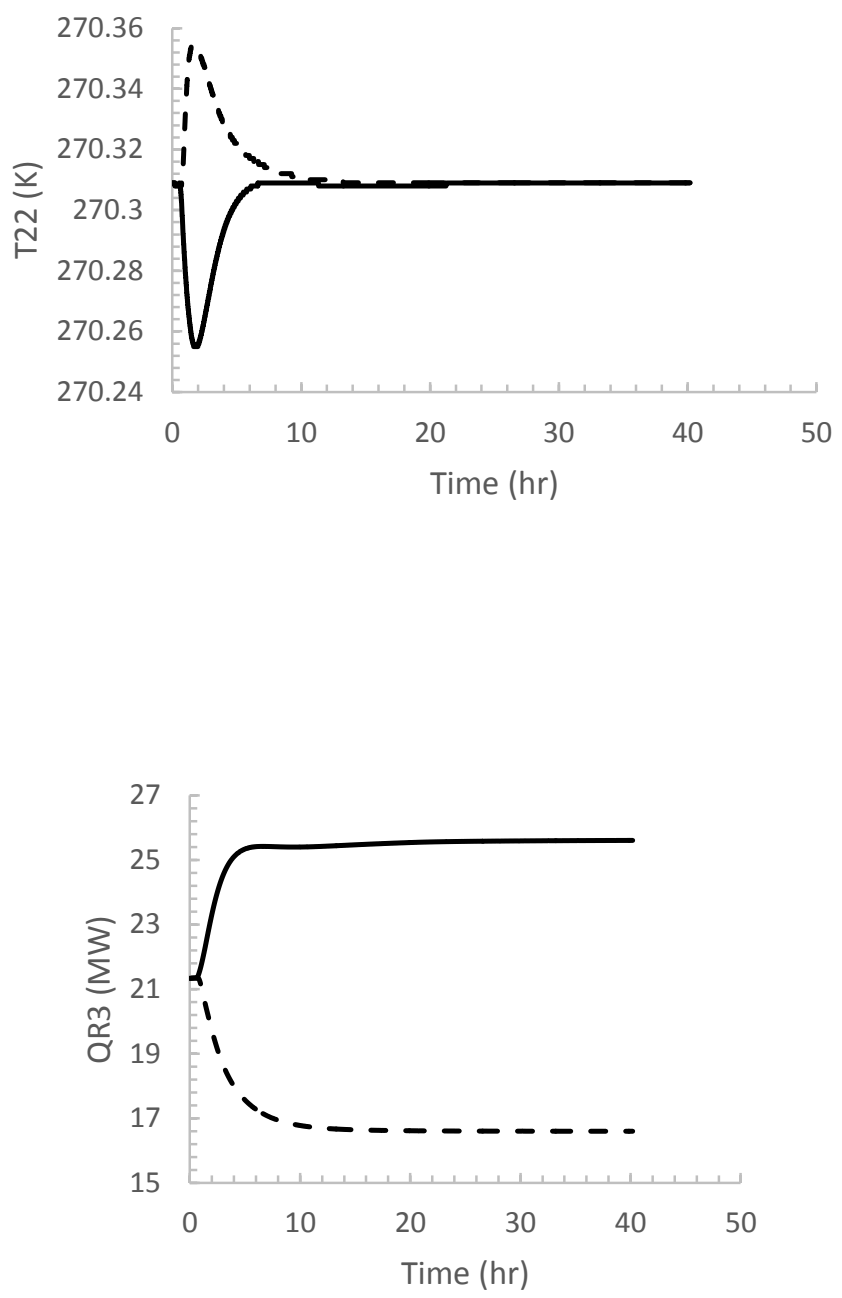

Figure 11. (a) Extractive column, (b) Recovery column, and (c) Concentrator column responses in the face of $\pm 20 \%$ fresh feed flowrate disturbances. 
(a)
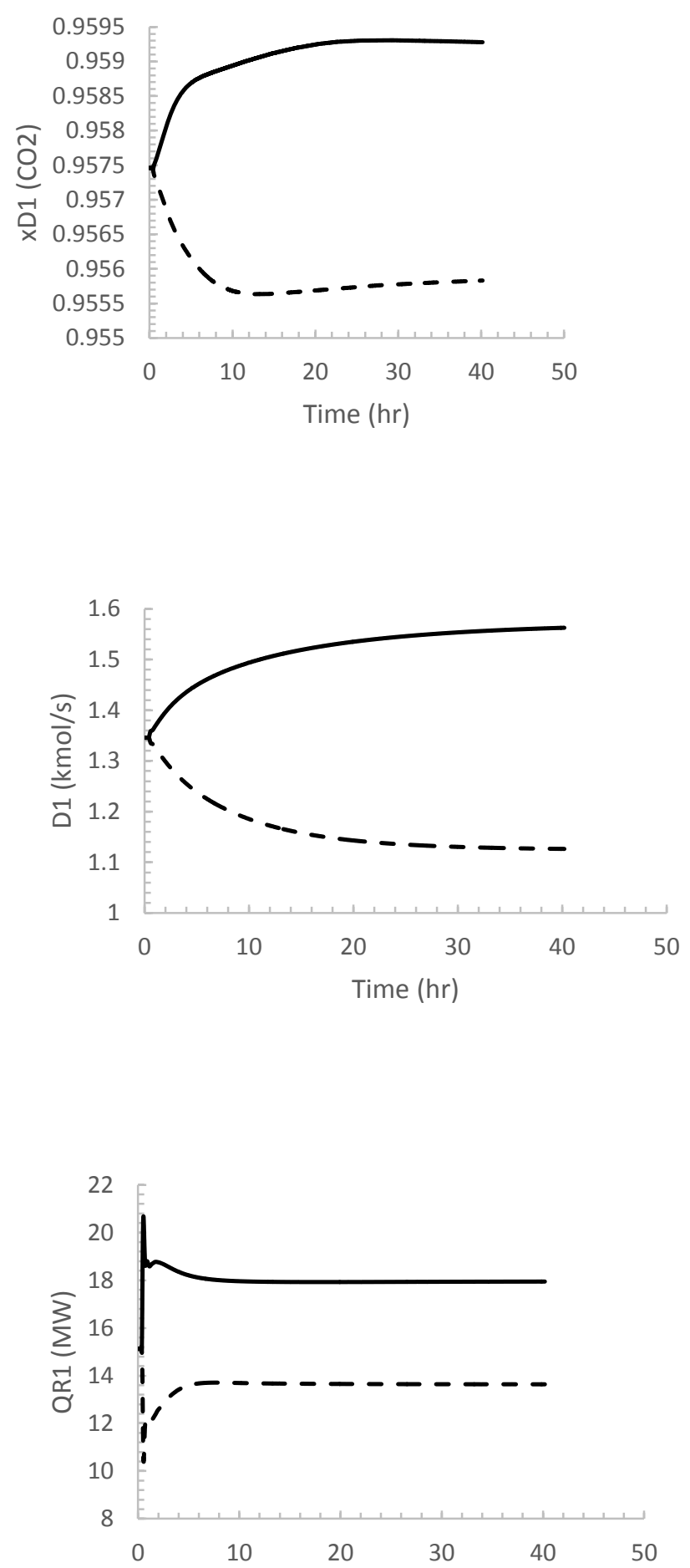

Time (hr)
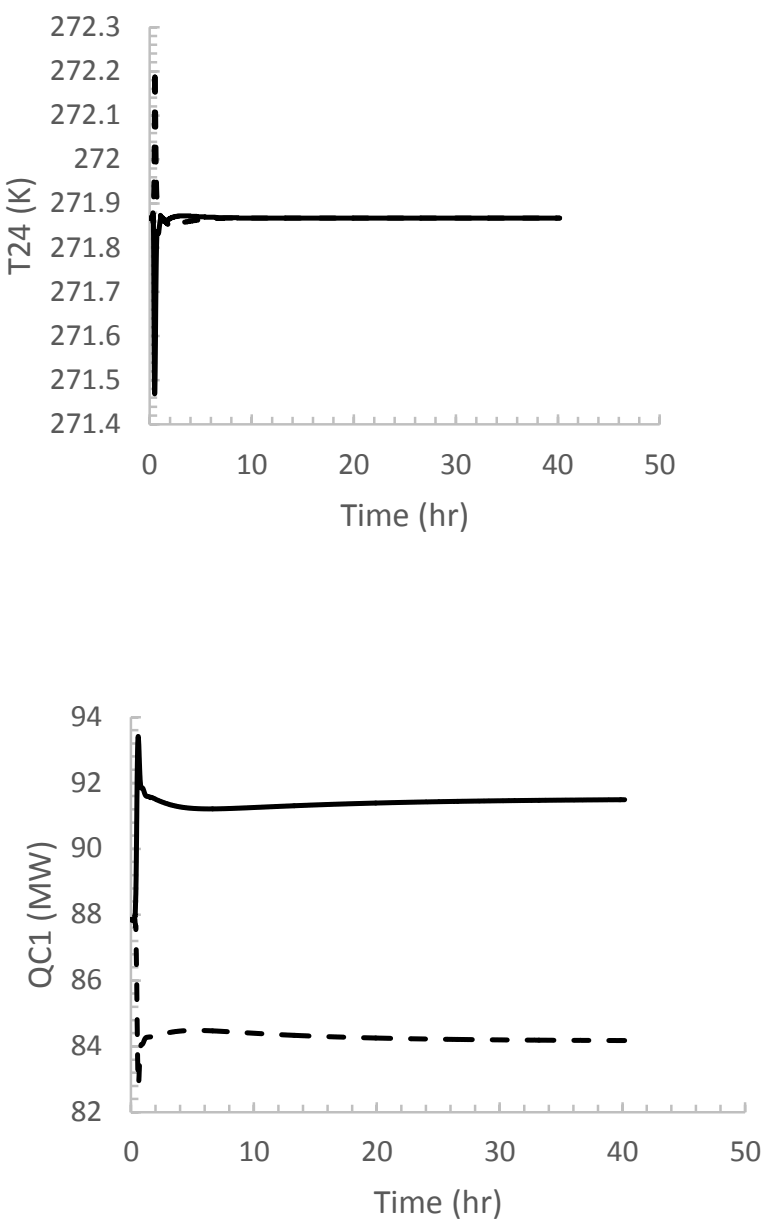
(b)
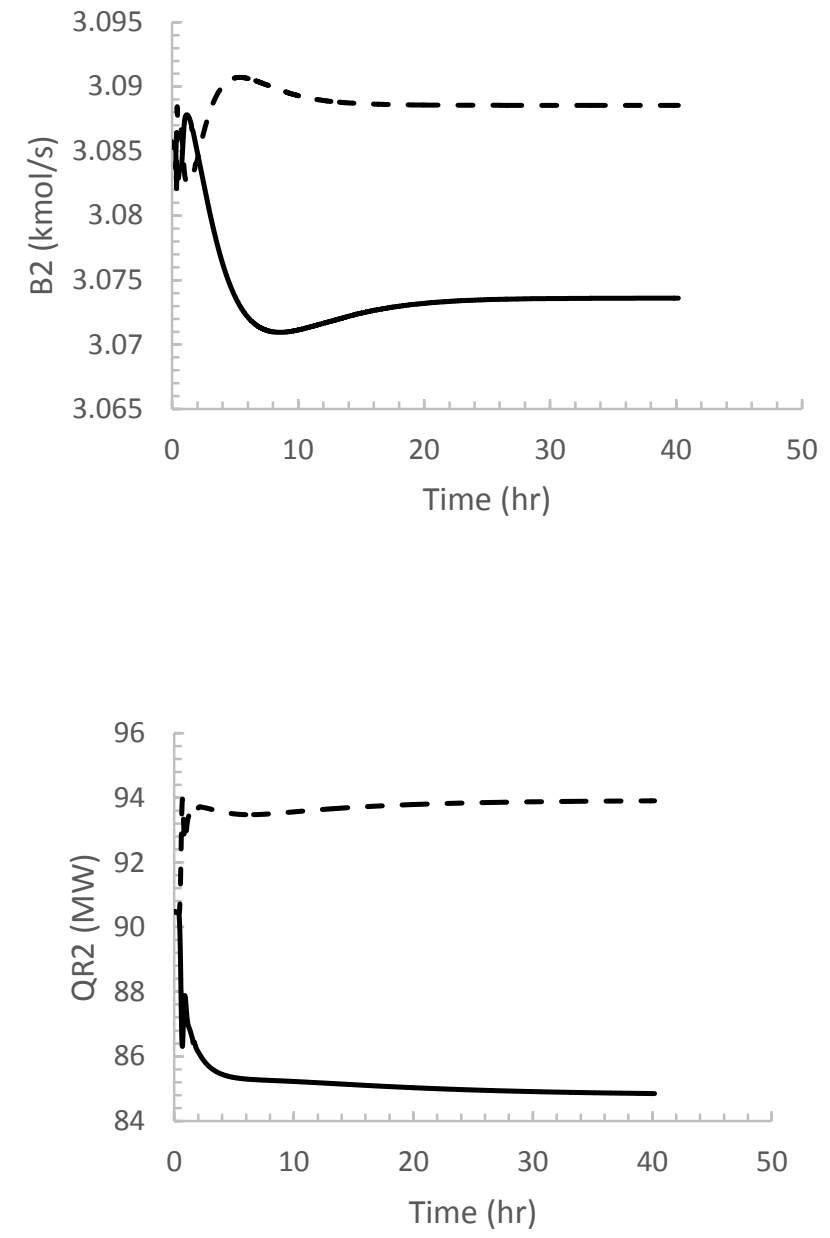
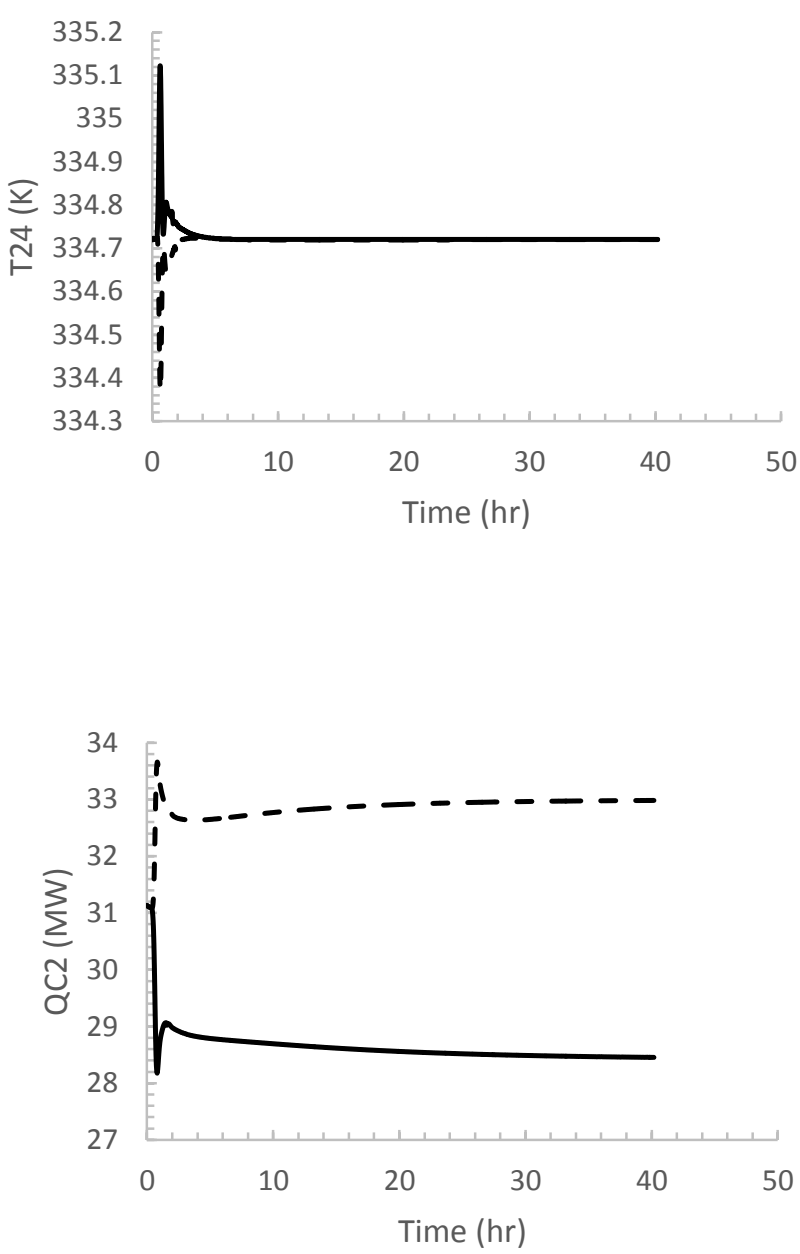

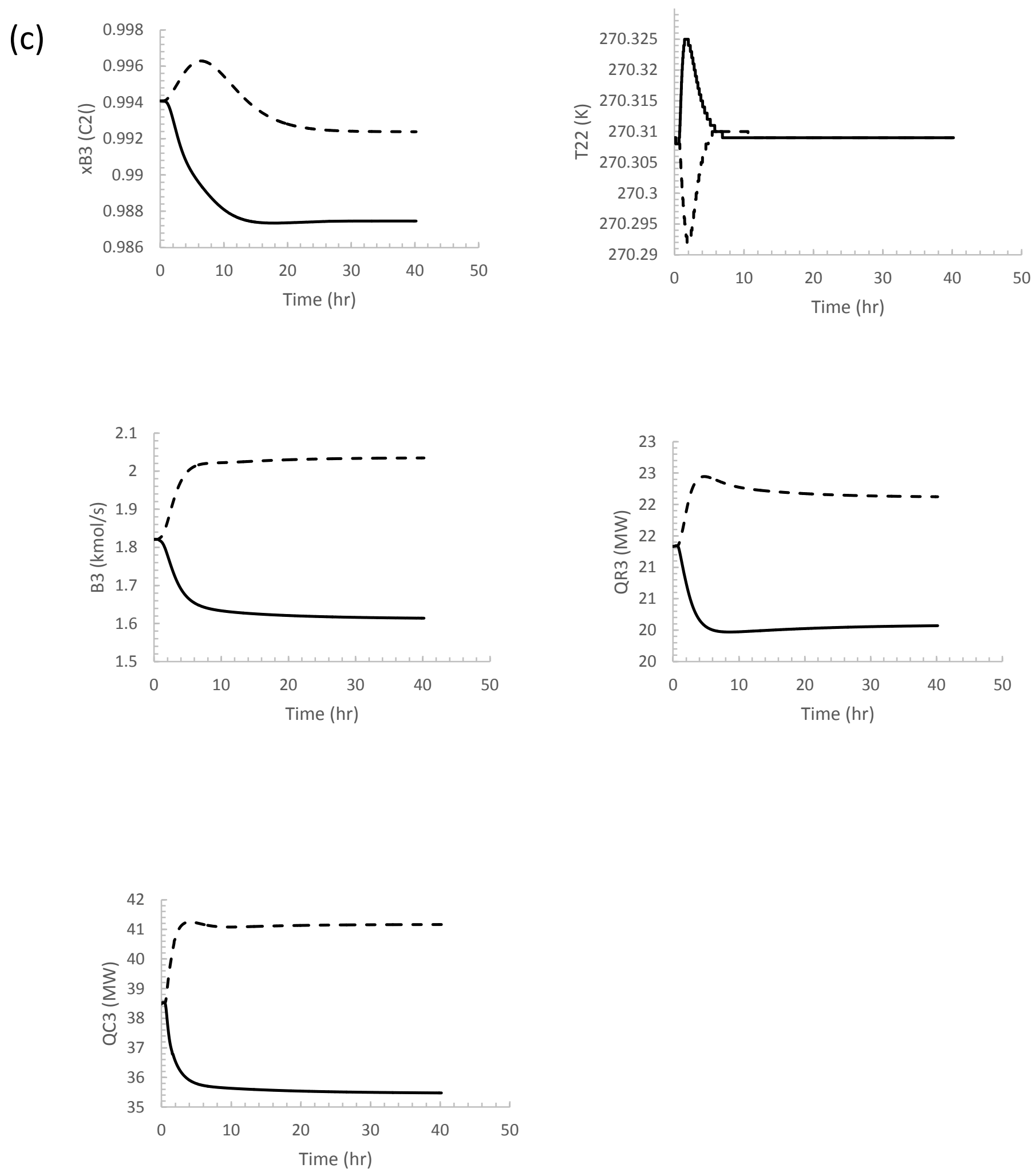

Figure 12. (a) Extractive column, (b) Recovery column, and (c) Concentrator column responses in the face of fresh feed composition disturbances. 